\title{
MODELLING AND ANALYSIS OF SWITCHING DC-TO-DC CONVERTERS IN CONSTANT-FREQUENCY CURRENT-PROGRAMMED MODE
}

\author{
SHI-PING HSU, ART BROWN, LOMAN RENSINK \\ AND R. D. MIDDLEBROOK \\ California Institute of Technology \\ Pasadena, California
}

\begin{abstract}
An analysis of $d c-t o-d c$ switching converters in constant-frequency current-prograrmed continuous conduction mode is performed, and leads to two significant results. The first is that a ramp function, used to eliminate a potential instability, can be chosen uniquely to assure both stability and the fastest possible transient response of the programmed current. The second is the development of an extension of the statespace averaging technique by means of which both the input and output small-signal properties of any such converter may be accurately represented by a linear small-signal equivalent-circuit model. The mode! is presented and experimentally verified for the $\bar{c} u k$ converter and for the conventional buck, boost, and buck-boost converters. All models exhibit basically a one-pole control-tooutput transfer function response.
\end{abstract}

\section{INTRODUCTION}

Over the last several years an effort has been made to characterize the transfer properties of dc-to-dc switching converters in the frequency domain. This program has culminated in the "statespace averaging" approach, and leads to generalized equivalent circuits ("canonical models") that express the line-to-output and control-to-output transfer properties. So far, equivalent circuits have been derived for the continuous and the discontinuous conduction modes of a converter operated in the conventional "duty-ratio programmed mode" in which the duty ratio appears as the external port at which feedback for regulation purposes is applied $[1,2]$.

At PESC 1978, two papers were presented [3, 4] in which a different "current-programmed mode" was

This work was sponsored in part by the International Business Machines Corporation, Kingston, $\mathrm{NY}$, and by the Naval Ocean Systems Center, San Diego, CA, contract N66001-78-C-0351 JAP, under support of the Research and Technology Directorate, Naval Electronic Systems Command, Washington, DC. employed. In this mode, the converter power switch duty ratio is determined by the times at which the switch current reaches a threshold value determined by a control signal. Thus, this threshold level, rather than the duty ratio, becomes the input port for feedback in the current-programmed mode. In [3], both the turn-on and turn-off times of the switch are determined in this manner, resulting in a free-running converter; in [4], the turn-on times are periodically clocked, leading to a fixed-frequency system, as shown in Fig. 1.
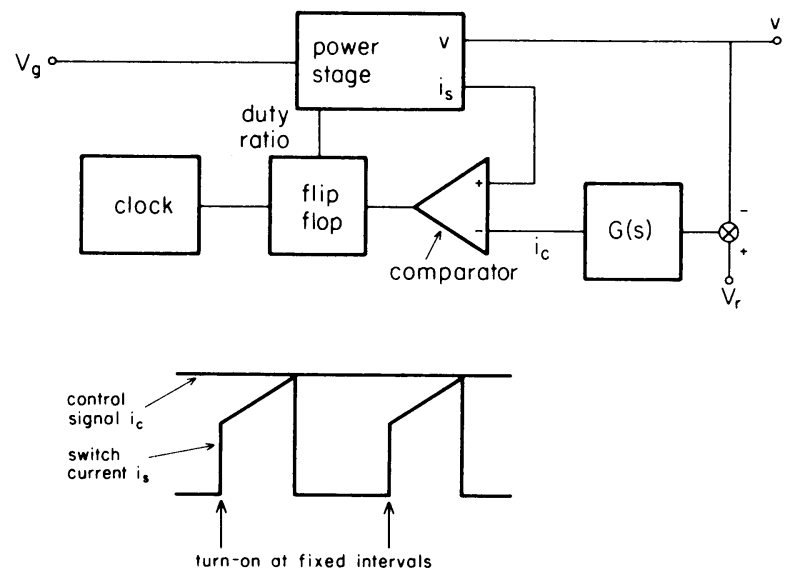

Fig. 1 Block diagram of constant-frequency currentprogramed control technique.

The current-programmed mode has several advantages over the conventional duty-ratio programmed scheme. First, since the switch, usually a transistor, is turned off when its current reaches the control signal level, failures due to excessive switch current can be prevented simply by limiting the maximum value of the control signal. This measure also protects the entire converter from overload damage. Second, several converters can be operated in parallel without a load-sharing problem, because all of the power switches receive the same control signal from the regulator feedback circuit and hence carry the same 
current. Third, as will be seen from this paper, the current-programmed mode, relative to dutyratio programming, effectively removes one pole from the loop gain, simplifying the design of the feedback network.

This paper is concerned with dc-to-dc converters operated in the fixed-frequency currentprogrammed mode and in continuous inductor conduction. One objective, as in previous work on the duty-ratio programmed mode, is to obtain small-signal equivalent circuit models which represent both the input and output properties, and which can then be embedded in the model of a complete regulator system, so that the overall dynamic properties and stability can be not only analyzed but also designed. However, for converters of this type more work is needed, because a fixed-frequency current-programmed converter is subject to oscillation even in the absence of regulator feedback. Hence, a second objective is to develop design techniques for eliminating this potential instability, and, if a range of solutions exists, picking the one which results in the best converter performance.

This notorious stability problem is discussed in Section 2, in which the cause of the possible oscillation is analyzed and a remedy for the problem is proposed. Section 3 contains the development of a modelling technique for currentprogrammed converters. After a brief review of state-space averaging, an integral part of the technique, the necessity of an extension of this method is demonstrated. Such an addition is then developed, and applied to the example of the Cuk converter. The section is concluded with a comparison of the dynamics of converters in the current-programmed mode with those of the same converters operated under duty-ratio programming. The salient feature of the current programmed continuous inductor current mode is that the control-to-output transfer function is basically one-pole, as is the duty ratio programmed discontinuous inductor conduction mode, but in contrast to the two-pole response in the conventional duty ratio programmed continuous conduction mode. In Section 4, refinement of the results of Section 3 is undertaken, leading to more accurate models appropriate for more sophisticated applications. Finally, in Section 5, experimental verification of the models for boost and Cuk converters [5] is presented.

\section{CURRENT-PROGRAMMING INSTABILITY: CAUSE AND REMEDY}

As mentioned in the introduction, a constantfrequency current-programmed converter is subject to instability even in the absence of external regulator feedback [4]. The cause of the problem lies in the fact that the current-programmed scheme constitutes an "internal" feedback loop: the level of the switch current determines when that same switch is turned off. It is found that the oscillation generally occurs when the duty ratio exceeds 0.5 , regardless of the type of converter.
A brief review of the nature of the instability is now presented. The effect can be explained with the help of the waveforms in Fig. 2 , which is a straight line plot of the inductor current which flows through the power switch when that switch is on. Straight lines well approximate current waveforms since system time constants are by design large compared to $\mathrm{T}_{\mathrm{S}}$. The control signal is also plotted.

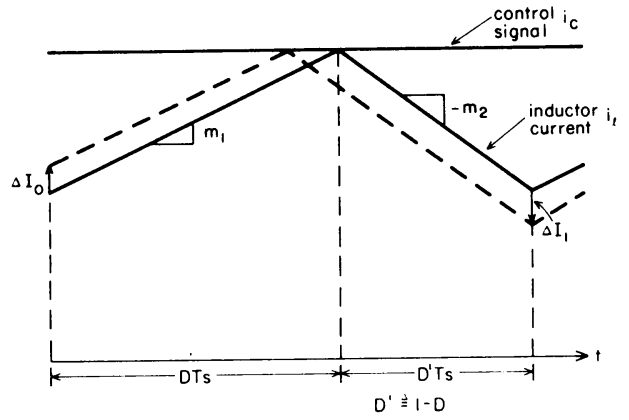

Fig. 2 Propagation of a perturbation in the programed current: instability occurs for $D>0.5$.

Suppose the inductor current has a rising slope $m_{1}$ and a falling slope $-m_{2}$ in steady state. Clearly, since the steady state ${ }^{2}$ waveform is periodic

$$
\frac{\mathrm{m}_{2}}{\mathrm{~m}_{1}}=\frac{\mathrm{D}}{\mathrm{D}^{\prime}}
$$

where $\mathrm{D}$ is the duty ratio and $\mathrm{D}^{\prime} \triangleq 1-\mathrm{D}$. If there is a perturbation, relative to the steady state, of $\Delta I_{0}$ in the inductor current at the beginning of a period, the waveforms show that after one cycle, the error will have become

$$
\Delta I_{1}=-\left(\frac{m_{2}}{m_{1}}\right) \Delta I_{0}=-\left(\frac{D}{D^{\prime}}\right) \Delta I_{0}
$$

Thus, after $\mathrm{n}$ cycles, the perturbation will be

$$
\Delta I_{n}=\left(-\frac{D}{D^{\prime}}\right)^{n} \Delta I_{0}
$$

Apparently, the "steady state" is not a stable solution if the duty ratio is greater than 0.5 .

As described in [4], this potential instability can be eliminated by the addition of a suitable cyclic artificial ramp to either the switch current waveform or to the control signal. Waveforms for this modification are shown in Fig. 3, in which the control signal is given a cyclic falling slope $-m$. An argument similar to that used previously shows that now a perturbation $\Delta \mathrm{I}_{\mathrm{o}}$ is carried into

$$
\Delta I_{n}=\left(-\frac{m_{2}-m}{m_{1}+m}\right)^{n} \Delta I_{0}
$$




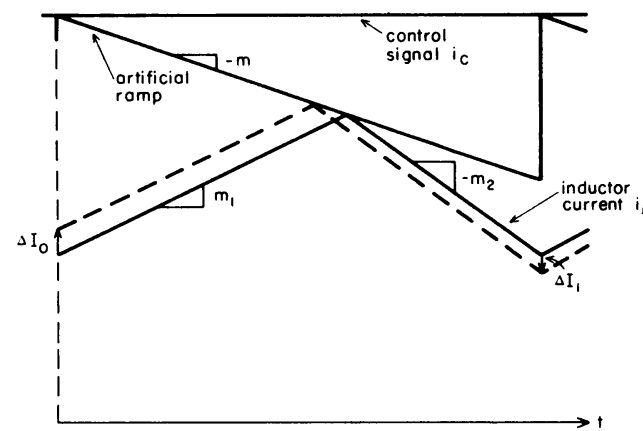

Fig. 3 Propagation of a perturbation in the progranmed current: in the presence of a suitable ramp, stability can be maintained for all $D$.

after n cycles. A suitable choice of the ramp slope $-m$ can thus cause this perturbation to die out, even if the duty ratio is greater than 0.5 . In particular, if $\mathrm{m}$ is chosen to be equal to $\mathrm{m}_{2}$, the magnitude of the falling current slope, (4) shows that any perturbation of the inductor current will disappear at the end of one cycle, thus guaranteeing inner loop stability and simultaneously providing the fastest possible transient response of the programmed current, as shown in Fig. 4.

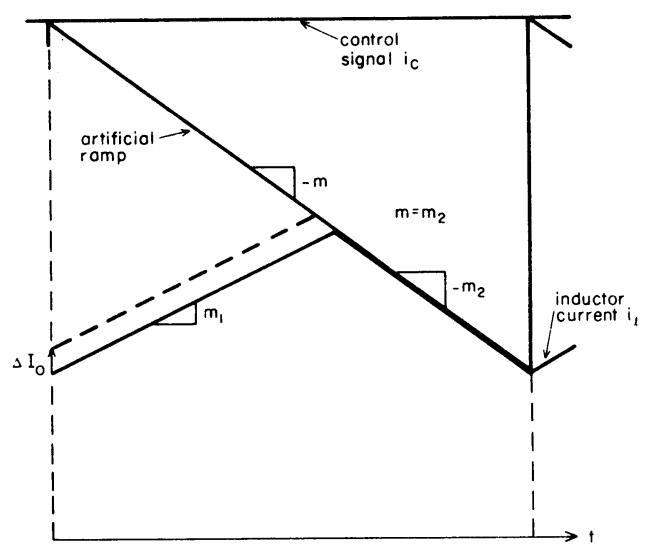

Fig. 4 Elimination of perturbation in one cycle when ramp slope equals falling current slope.

Note, for duty ratios less than 0.5 , that while the system will be stable in the absence of an artificial ramp, even in these situations the best possible transient response is only attained if a ramp of the correct slope is used. Thus, this compensation scheme benefits system performance for any operating condition, not just cases where an artificial ramp is required to avoid instability. The same results hold if an artificial ramp of slope $m$ is added to the switch current instead of to the control signal.
In connection with these findings, two practical items should be mentioned. First, if the switch current is monitored with a transformer, its magnetizing current acts as a destabilizing ramp. Hence, in the absence of an artificial ramp, the minimum value of duty ratio for which oscillation occurs is less than 0.5 . Likewise, an artificial ramp would have to be adjusted to compensate for this additional influence. The second point is that the slope $\mathrm{m}_{2}$ may change with operating conditions. In this case, if a fixed linear ramp is used, the benefit of single-cycle elimination of errors is achieved at only one operating point. More sophisticated ramps might be used to overcome this problem.

\section{MODELLING AND ANALYSIS}

\subsection{Review of State-Space Averaging Method, Continuous Conduction Mode}

The state-space averaging method has been developed to determine the small-signal 1ine-tooutput and duty-ratio-to-output transfer properties of converters operated in both the continuous and discontinuous conduction modes $[1,2]$. Since the results of this technique are used as part of the basis for modelling converters operated in the current-programmed mode, a brief review of the state-space averaging method for the continuous conduction case is presented here.

The state-space averaging technique, outlined in Fig. 5, begins with a description of the converter topologies appearing during one cycle of operation. During the interval $\mathrm{dT}_{\mathrm{s}}$, $\mathrm{d}$ being the duty ratio, when the switch is $s$ closed the converter can be described by a set of linear, time-invariant differential equations

$$
\dot{\mathrm{x}}=\mathrm{A}_{1} \mathrm{x}+\mathrm{b}_{1} \mathrm{~V}_{\mathrm{g}}
$$

where $\mathrm{x}$ is a state vector of inductor currents and capacitor voltages. Similarly, it can be described by another set of linear differential equations

$$
\dot{x}=A_{2} x+b_{2} V_{g}
$$

during the interval $d^{\prime} T \triangleq(1-d) T$, when the switch is open, as shown in box 2 of Fig. 5. These two sets of equations can be combined in an average sense to produce a single matrix differential equation, also shown in box 3 of Fig. 5,

$$
\dot{\mathrm{x}}=\mathrm{A} \mathrm{x}+\mathrm{b} \mathrm{v}_{\mathrm{g}}
$$

where

$$
\begin{aligned}
& A \triangleq d_{1}+d^{\prime} A_{2} \\
& b \triangleq d b_{1}+d^{\prime} b_{2}
\end{aligned}
$$

which describes the averaged behavior of the converter, that is, with the switching ripple filtered from the state variables. 

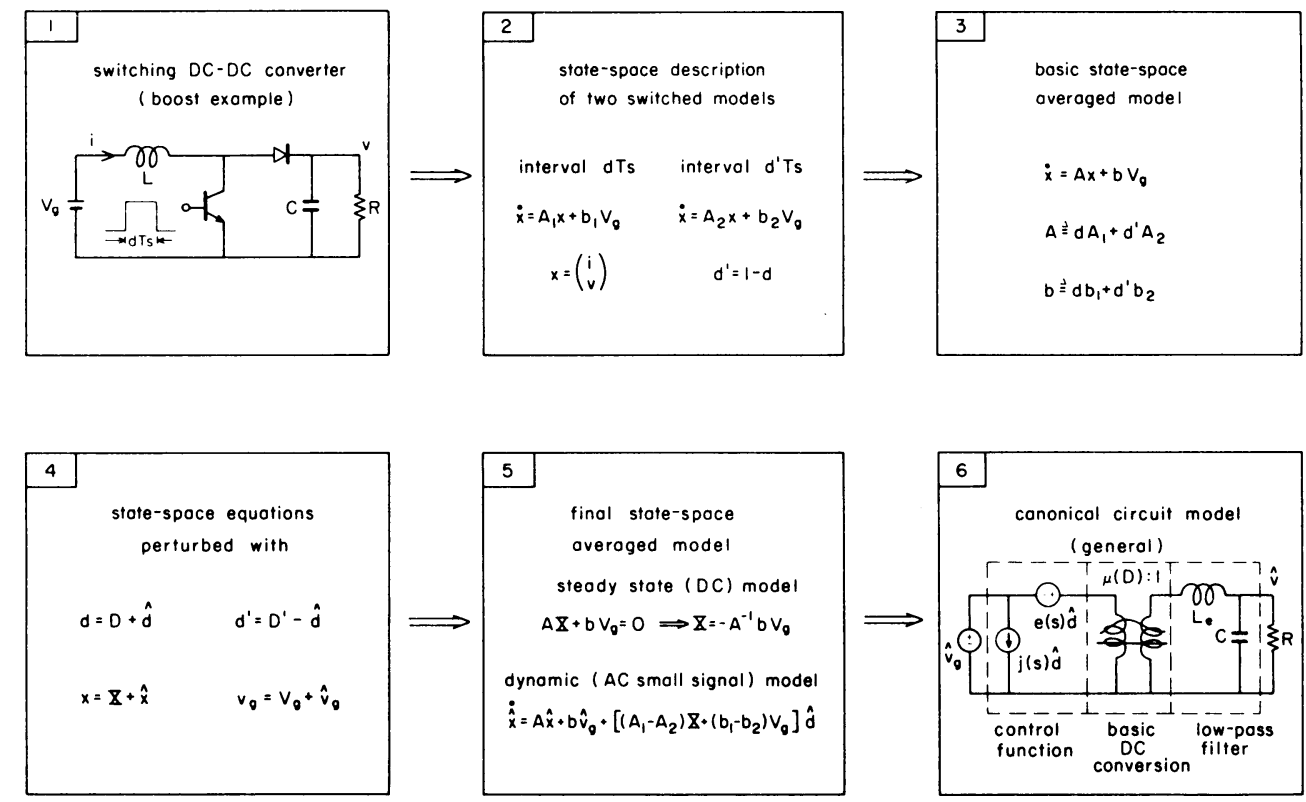

Fig. 5 Flowchart of state-space averaging method for modelling $d c$-to-dc switching converters in the duty ratio programed continuous conduction mode.

Note that the matrices $A$ and $b$ may be dutyratio dependent, which means that the averaged equation may be nonlinear with respect to duty ratio. Since the ultimate goal is to find an equivalent linear circuit model, the analysis is to be restricted to the linear domain. Hence, as in box 4 of Fig. 5, the averaged equation is perturbed around the operating point by substitution into (7) of

$$
\begin{aligned}
& d=D+\hat{d} \\
& x=x+\hat{x} \\
& v_{g}=v_{g}+\hat{v}_{g}
\end{aligned}
$$

where capitalized quantities refer to steady state values and carets indicate small perturbations. Upon expansion of the result and retention of only first-order terms in the perturbations, the final state-space averaged equations are obtained (represented in box 5 of Fig. 5):

$$
\begin{aligned}
& \text { Steady state } \quad \mathrm{AX}+\mathrm{bV}_{\mathrm{g}}=0 \\
& \text { operating point } \\
& \text { ac small-signal } \quad \dot{\hat{x}}=A \hat{x}+b \hat{v}_{g} \\
& +\left[\left(A_{1}-A_{2}\right) x+\left(b_{1}-b_{2}\right) v_{g}\right] \hat{d} \\
& \mathrm{~A}=\mathrm{DA}_{1}+\mathrm{D}^{\prime} \mathrm{A}_{2} \\
& \mathrm{~b}=\mathrm{Db}_{1}+\mathrm{D}^{\prime} \mathrm{b}_{2}
\end{aligned}
$$

The small-signal equivalent circuit model can then be derived from (10).

In summary, the smal1-signal low-frequency behavior of the converter in box 1 of Fig. 5, including both input and output properties, has been represented by the canonical model in box 6 of Fig. 5, through the averaging, perturbation and linearization process.

\subsection{Necessity of an Extension of the State-Space Averaging Method for Current-Programming}

State-space averaged equation (10) was developed, in part, to facilitate rational design of feedback networks for switching regulators. I t the conventional single-state feedback approach, illustrated in Fig. 6, duty ratio variations are related to variations in the output voltage by a compensation network:

$$
\hat{\mathrm{d}}=-\mathrm{G}(\mathrm{s}) \hat{\mathrm{v}}, \quad \hat{\mathrm{v}}_{\mathrm{r}}=0
$$

From (10), the transfer function characterizing the "forward" path from the duty ratio through the power stage to the output voltage can be found:

$$
\hat{\mathrm{v}}=F(\mathrm{~s}) \hat{\mathrm{d}}
$$

Then the product $F(s) G(s)$ is the loop gain of the regulator, and a Nyquist or Bode plot analysis of this loop gain allows determination of $G(s)$ such that stability and a large system bandwidth are simultaneously achieved. 


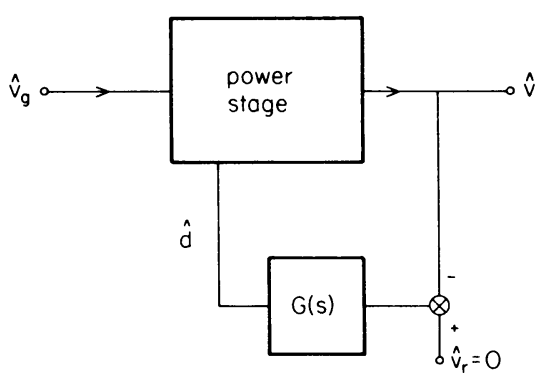

Fig. 6 Reduced block diagram of regulator, incorporating the small-signal linear equivalent circuit model of the power stage, in duty ratio programmed mode as expressed in statespace averaged equation (10).

Current-programming, however, is clearly different from this conventional single-state feedback approach, since both the output voltage and the switch current are directly involved in determination of the duty ratio. In such multistate feedback systems, it is still possible to define a loop gain in such a manner that the Nyquist stability criterion can be used. However, the calculation of this loop gain is more difficult than in the conventional case, and formulas for other quantities of interest, such as the closed-loop line rejection, do not retain the simple form they possess when only a single state is fed back.

Thus, motivation exists for the development of an extension of the state-space averaging method for the current-programming case, in order to avoid these difficulties. The search is aided by the recognition of a characteristic of current programming not generally found in other multi-state feedback systems: while usually several compensation elements, one for each fedback state, must be designed simultaneously, in the case of current programming the current feedback loop can be specified, as in Section 2, independently of regulator feedback. Hence, only the voltage feedback compensation $\mathrm{G}(\mathrm{s})$ is to be determined. Thus, if the previously designed current loop is absorbed into the "forward" converter path, as in Fig. 7, the

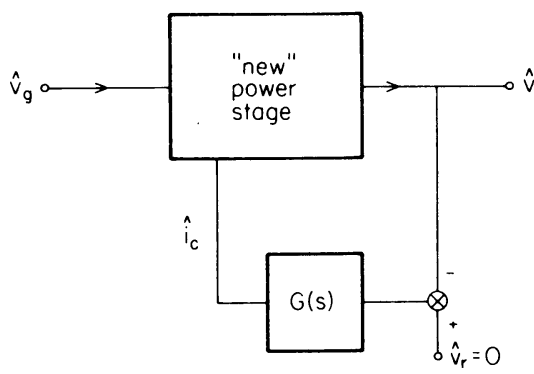

Fig. 7 Reduced block diagram of regulator, incorporating the desired small-signal linear equivalent circuit model of the power stage in current-progranmed mode. small-signal properties of this new system are described by a linear mode1, independent of regulator feedback compensation to be chosen, with inputs $\hat{v}$ and $\hat{i}$. Note that only a single, simple feedback loop is evident, the other, more complicated path being now an intrinsic part of the converter model. With such a model, determination of the compensation $\mathrm{G}(\mathrm{s})$ is accomplished by the same simple single-state feedback analysis as that described at the beginning of this section for the duty-ratio programmed mode, with $\hat{i}_{c}$ taking the place of $\hat{d}$.

With this motivation, then, the development of the desired extension of the modelling technique is undertaken.

\subsection{Modelling Technique for Converters in Current-Programmed Mode}

The current-programmed system in Fig. 7 can be described by a set of linear differential equations of the form

$$
s \hat{x}=A^{\prime} \hat{x}+b^{\prime} \hat{v}_{g}+c^{\prime} \hat{i}_{c}
$$

with $\hat{v}_{\text {and }} \hat{i}_{\text {as }}$ ase two inputs to the system. Note that Laplace transforms are used throughout this section. The problem, then, is to determine $A^{\prime}, b^{\prime}$, and $c^{\prime}$. Once they are known, an equivalent circuit model can be inferred from (13).

The technique used in arriving at the currentprogrammed state equation (13) is outlined in Fig. 8. Two pieces of information are used:

1) the state-space averaged equation

$$
s \hat{x}=A \hat{x}+b \hat{v}_{g}+c \hat{d}
$$

which, as discussed in Section 3.1, can be found for any converter, and

2) a description of the effects of the current feedback loop, in the form of a control constraint relating variations $\hat{i}_{\ell}$ in the programmed current to control variations $\hat{i}_{\text {, }}$, and possibly also variations in other states $\hat{x}$, the input voltage $\hat{v}_{g}$, and duty ratio $\mathrm{d}$ :

$$
\hat{i}_{l}=f_{1}\left(\hat{i}_{c}, \hat{x}_{,}, \hat{v}_{g}, \hat{d}\right)
$$

These two pieces of information are combined on the basis of the intuitive notion that the programmed inductor current is changed in status from an unknown state to a "driving" term, while the duty-ratio modulation loses its importance as an independent input. In mathematical expression of this idea, the state equation for $\hat{i}_{\ell}$ from the state-space averaged equation (14) is used to solve for $\hat{d}$, which results in a duty ratio expression

$$
\hat{\mathrm{d}}=g\left(\hat{x}, \hat{v}_{g}, s \hat{i}_{\ell}\right)
$$


This expression for $\hat{d}$ is then substituted into (14), and all terms involving $\hat{i}_{\ell}$ are collected as part of a new "driving" term. The result is a reformulated version of (14):

$$
s \hat{x}=A^{\prime \prime} \hat{x}+b^{\prime \prime} \hat{v}_{g}+c^{\prime \prime} \hat{i}_{\ell}
$$

Note that the state equation for $\hat{i}_{\ell}$ is now just $s \hat{i}_{\ell}=s \hat{i}_{\ell}$; the duty ratio expressions (16) combined with (17) have the same number of independent equations as state-space averaged equation (14), from which they were derived.
Equation (17), of course, still does not describe the current-programmed mode, since it was derived solely from the state-space averaged equation (14). However, it is now an easy matter to insert the second piece of information, the description of the effects of the current loop detailed in the control constraint (15). First, the duty ratio expression (16) is used to eliminate $\hat{d}$ from (15), resulting in an auxiliary relation for $\hat{i}_{\ell}$ in which $\hat{\mathrm{d}}$ does not appear:

$$
\hat{i}_{\ell}=f_{2}\left(\hat{i}_{c}, \hat{x}, \hat{v}_{g}\right)
$$

STATE-SPACE AVERAGED EQUATION

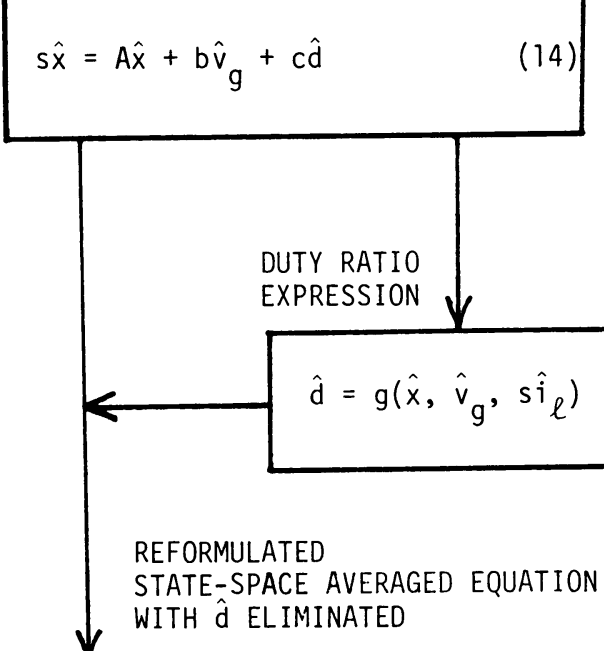

CONTROL CONSTRAINT

$$
\hat{i}_{\ell}=f_{1}\left(\hat{i}_{c}, \hat{x}, \hat{v}_{g}, \hat{d}\right)
$$

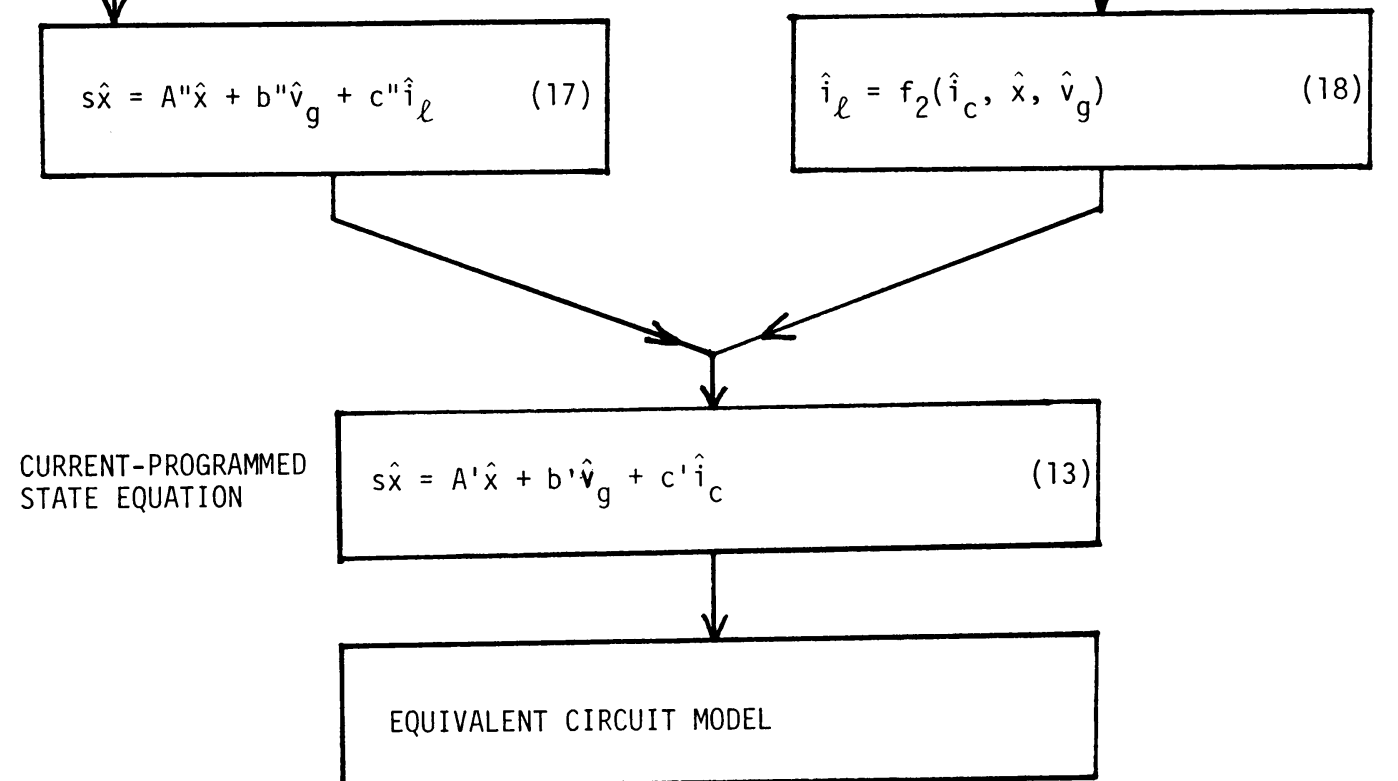

Fig. 8 Algorithm for modelling converters in current-programed continuous conduction mode. 
This auxiliary relation (18) is then substituted into the reformulated version (17) of the statespace averaged equation, and after terms are collected, the desired current-programmed state equation (13), rewritten here, is obtained:

$$
s \hat{x}=A^{\prime} \hat{x}+b^{\prime} \hat{v}_{g}+c^{\prime} \hat{i}_{c}
$$

Equation (13) is then used to generate an equivalent circuit model.

The only point remaining to be discussed is the nature of the control constrint (15), the description of the effects of the current feedback. Two versions of this equation are discussed in this paper. The first, simpler version is based on the waveforms of Fig. 9, in which the programmed current $i_{\ell}$ and the control i are plotted. From this figure, it appears that variations in the inductor current $i_{f}$ follow variations in the control $i$ rather closely. Indeed, as an approximation, it may be said that

$$
\hat{i}_{\ell}=\hat{i}_{c}
$$

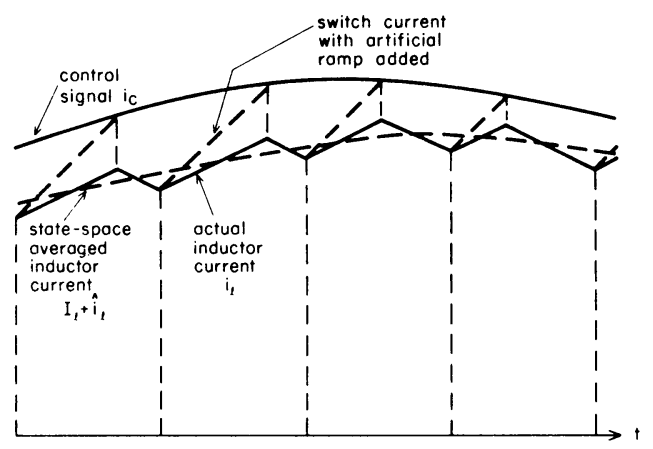

Fig. 9 Behavior of programmed current $i_{p}$ in response to variations in control current $i_{c}$.

But this equation is in precisely the form of the control constraint (15), and so is used as such. Note that in this case the desired currentprogrammed state equation (13) is identical to the reformulated state-space averaged equation (17) with $\hat{i}_{\text {f }}$ replaced by $\hat{i}$, that is, $A^{\prime}=A^{\prime \prime}$, $b^{\prime}=b^{\prime \prime}$, and $c^{\prime}=c^{\prime \prime}$. Notê also that the simple control constraint (19) implies directly that the current $i_{\ell}$ is no longer a state; hence, the order of the system is reduced by one.

It is important to remember that the control constraint (19) is only an approximation. In Section 4, a second, more accurate version of (15) will be introduced, one which leads to more accurate models. However, for many purposes, (19) is adequate to describe the effects of the current feedback, and will be used throughout the remainder of this section.

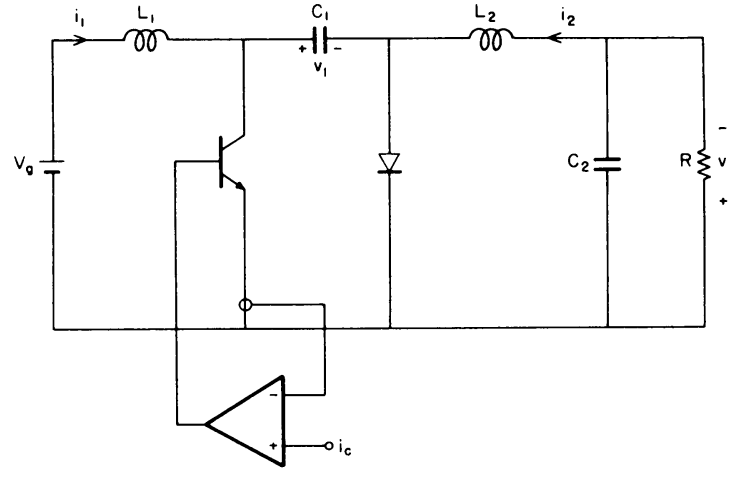

Fig. 10 Current-programmed Ćuk converter.

\subsection{Example: Current-Programmed Cuk Converter}

The method developed in Section 3.3 is applied here to the current-programmed Cuk converter of Fig. 10. With the assumption of ideal switches, the two switched topologies are as shown in Fig. 11. With the choice of state vector

$$
x=\left(i_{1}, i_{2}, v_{1}, v\right)^{T}
$$

the state equations are:

i) interval $\mathrm{dT}_{\mathrm{s}}$ : $\dot{\mathrm{x}}=\mathrm{A}_{1} \mathrm{x}+\mathrm{b}_{1} \mathrm{v}_{\mathrm{g}}$, or

$\frac{\mathrm{d}}{\mathrm{dt}}\left[\begin{array}{c}\mathrm{i}_{1} \\ \mathrm{i}_{2} \\ \mathrm{v}_{1} \\ \mathrm{v}\end{array}\right]=\left[\begin{array}{cccc}0 & 0 & 0 & 0 \\ 0 & 0 & \frac{1}{\mathrm{~L}_{2}} & -\frac{1}{\mathrm{~L}_{2}} \\ 0 & -\frac{1}{\mathrm{C}_{1}} & 0 & 0 \\ 0 & \frac{1}{\mathrm{C}_{2}} & 0 & -\frac{1}{\mathrm{C}_{2} \mathrm{R}}\end{array}\right]\left[\begin{array}{c}\mathrm{i}_{1} \\ \mathrm{i}_{2} \\ \mathrm{v}_{1} \\ \mathrm{v}\end{array}\right]+\left[\begin{array}{l}\frac{1}{\mathrm{~L}_{1}} \\ 0 \\ 0 \\ 0\end{array}\right] \mathrm{v}_{\mathrm{g}}$

ii) interval $\mathrm{d}^{\prime} \mathrm{T}_{\mathrm{s}}$ : $\dot{\mathrm{x}}=\mathrm{A}_{2} \mathrm{x}+\mathrm{b}_{2} \mathrm{v}_{\mathrm{g}}$, or

$\frac{d}{d t}\left(\begin{array}{c}i_{1} \\ i_{2} \\ v_{1} \\ v\end{array}\right)=\left(\begin{array}{cccc}0 & 0 & -\frac{1}{L_{1}} & 0 \\ 0 & 0 & 0 & -\frac{1}{L_{2}} \\ \frac{1}{C_{1}} & 0 & 0 & 0 \\ 0 & \frac{1}{C_{2}} & 0 & -\frac{1}{\mathrm{C}_{2} \mathrm{R}}\end{array}\right]\left(\begin{array}{c}i_{1} \\ i_{2} \\ v_{1} \\ v\end{array}\right)+\left(\begin{array}{c}\frac{1}{\mathrm{~L}_{1}} \\ 0 \\ 0 \\ 0\end{array}\right) v_{g}$

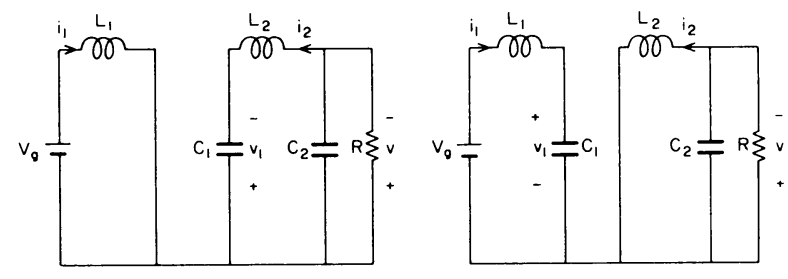

Fig. 11 The two switched circuit models for the converter of Fig. 10. 
With use of (10), the small signal dynamic model of the Cuk converter is

$$
\dot{\hat{x}}=A \hat{x}+b \hat{v}_{g}+\left[\left(A_{1}-A_{2}\right) x+\left(b_{1}-b_{2}\right) v_{g}\right] \hat{d}
$$

or, after taking Laplace transforms,

$$
\begin{aligned}
& {\left[\begin{array}{l}
\hat{s}_{1}(s) \\
\hat{s}_{2}(s) \\
\hat{s}_{1}(s) \\
\hat{s}(s)
\end{array}\right]=\left[\begin{array}{cccc}
0 & 0 & -\frac{D^{\prime}}{\mathrm{L}_{1}} & 0 \\
0 & 0 & \frac{\mathrm{D}}{\mathrm{L}_{2}} & -\frac{1}{\mathrm{~L}_{2}} \\
\frac{\mathrm{D}^{\prime}}{\mathrm{C}_{1}} & -\frac{\mathrm{D}}{\mathrm{C}_{1}} & 0 & 0 \\
0 & \frac{1}{\mathrm{C}_{2}} & 0 & -\frac{1}{\mathrm{C}_{2} \mathrm{R}}
\end{array}\right]\left[\begin{array}{c}
\hat{\mathrm{i}}_{1}(s) \\
\hat{\mathrm{i}}_{2}(s) \\
\hat{\mathrm{v}}_{1}(s) \\
\hat{v}(s)
\end{array}\right]} \\
& +\left[\begin{array}{c}
\frac{1}{\mathrm{~L}_{1}} \\
0 \\
0 \\
0
\end{array}\right] \hat{\mathrm{v}}_{\mathrm{g}}+\left[\begin{array}{c}
\frac{\mathrm{v}_{1}}{\mathrm{~L}_{1}} \\
\frac{\mathrm{v}_{1}}{\mathrm{~L}_{2}} \\
\mathrm{I}_{1}+\mathrm{I}_{2} \\
-\frac{\mathrm{C}_{1}}{0}
\end{array}\right] \hat{\mathrm{d}}(\mathrm{s})
\end{aligned}
$$

where $V_{1}, I_{1}, I_{2}$, and $D$ are steady-state dc values.

In the Cuk converter, the programmed current is actually the sum of the two inductor currents, since that is the current through the switch when it is closed. Therefore, duty ratio expression (16) is found by summation of (23) and (24), and solution for $\hat{d}$. The result is

$$
\hat{\mathrm{d}}(\mathrm{s})=\frac{1}{\mathrm{v}_{1}} \frac{\mathrm{L}_{1} \mathrm{~L}_{2}}{\mathrm{~L}_{1}+\mathrm{L}_{2}}\left[s\left(\hat{\mathrm{i}}_{1}+\hat{\mathrm{i}}_{2}\right)+\left(\frac{\mathrm{D}^{\prime}}{\mathrm{L}_{1}}-\frac{\mathrm{D}}{\mathrm{L}_{2}}\right) \hat{\mathrm{v}}_{1}+\frac{\hat{\mathrm{v}}}{\mathrm{L}_{2}}-\frac{\hat{\mathrm{v}}_{\mathrm{g}}}{\mathrm{L}_{1}}\right](27)
$$

Next, the reformulated state-space averaged equation (17) is achieved by substitution of (27) into equations (23)-(26). In the same step, the control constraint (15), in this case

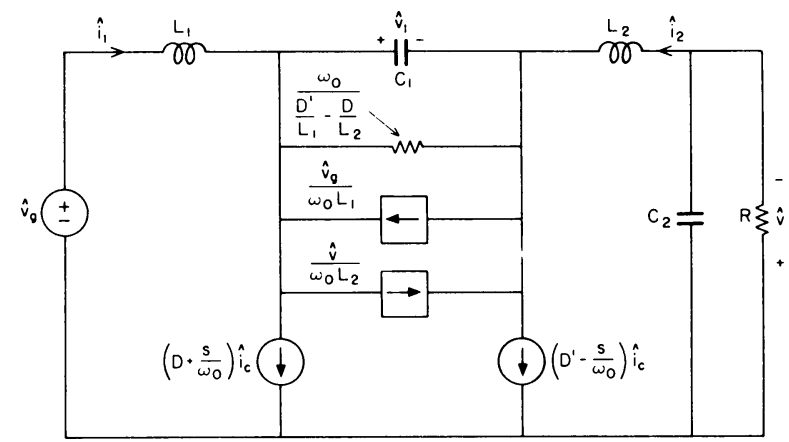

Fia. 12 Preliminary form of the equivalent. circuit model for the current-programed cuk converter in continuous conduction mode.

$$
\hat{i}_{1}+\hat{i}_{2}=\hat{i}_{c}
$$

is substituted. Then the current-programmed state equation is obtained

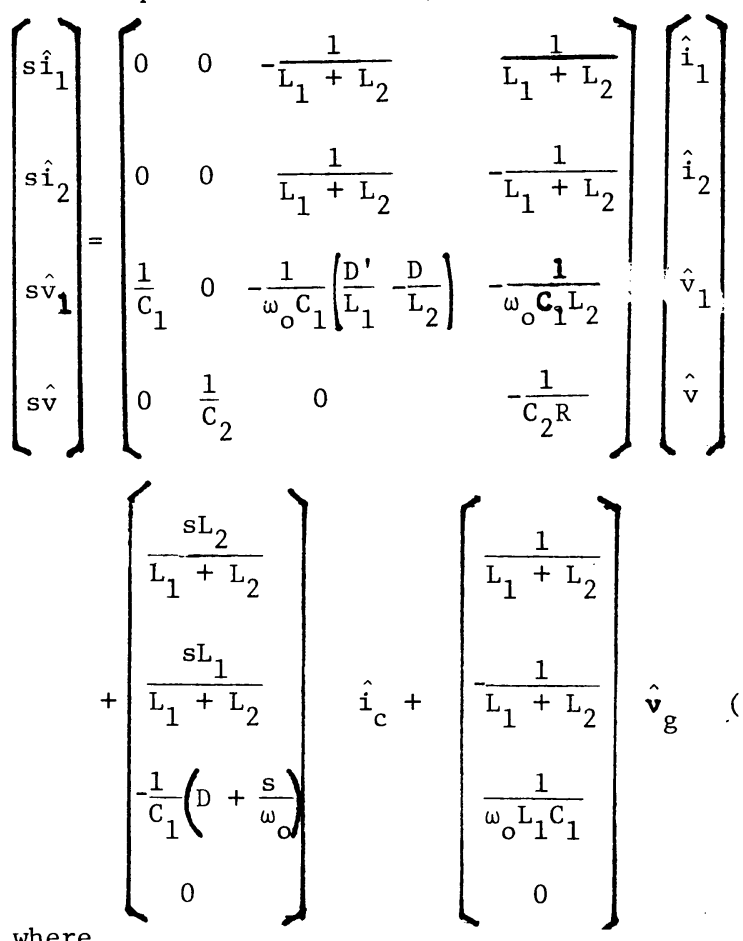

where

$$
\omega_{0} \triangleq \mathrm{R}_{\mathrm{N}} /\left(\mathrm{L}_{1}|| \mathrm{L}_{2}\right)
$$

in which

$$
\mathrm{R}_{\mathrm{N}} \triangleq \frac{\mathrm{V}_{1}}{\mathrm{I}_{1}+\mathrm{I}_{2}}
$$

According to (31), $R$ is the ratio of the dc voltage across $C_{1}$ to the ${ }^{\mathrm{N}}$ sum of the input and output inductor dc currents. Since the output inductor dc current $I_{2}$ is equal to the dc load current $I$, and since the capacitor $C_{1}$ dc voltage $V_{1}$ is equal to the sum of the converter dc input and output voltage $v_{g}+v$, it follows that

$$
\mathrm{R}_{\mathrm{N}}=\frac{\mathrm{V}_{1}}{\mathrm{I}_{1}+\mathrm{I}_{2}}=\frac{\mathrm{V}_{\mathrm{g}}+\mathrm{V}}{\mathrm{I}_{1}+\mathrm{I}}=\frac{\mathrm{D}^{\prime}}{\mathrm{D}} \frac{\mathrm{V}}{\mathrm{I}}=\frac{\mathrm{D}^{\prime} \mathrm{R}}{\mathrm{D}}
$$

in which the basic converter dc relations $\mathrm{V} / \mathrm{V}_{\mathrm{g}}=$ $\mathrm{I}_{1} / \mathrm{I}=\mathrm{D} / \mathrm{D}^{\prime}$ have been used, and

$$
\mathrm{R} \triangleq \frac{\mathrm{V}}{\mathrm{I}}=\frac{\mathrm{dc} \text { output voltage }}{\mathrm{dc} \text { output current }}
$$

Hence, for normal ranges of duty ratio, $R_{\text {is }}$ is the same order of magnitude as $R$. Note that even if the converter is connected to complex or active loads, the value of the parameter $R$ to be used is still V/I. An equivalent circuit model for (29) is shown in Fig. 12. Note that here and in all 
circuits appearing in this paper, independent generators are represented by circles, while dependent sources are drawn as squares. This model can be simplified through use of (28) and of the substitutions

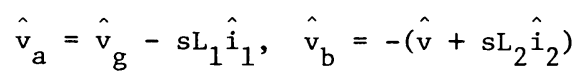

The result is shown in Fig. 13.
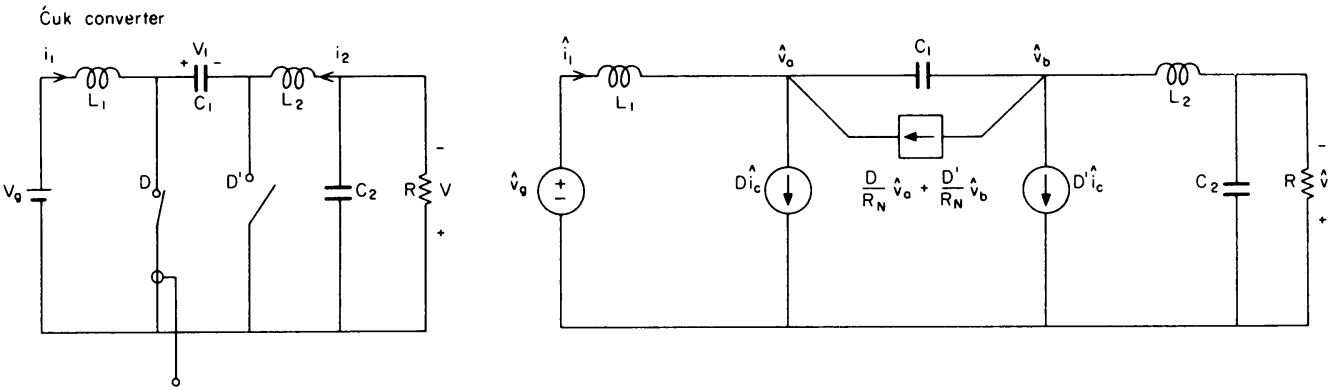

Fig. 13 Basic circuit and its "simple" small-signal equivalent circuit model of the Cuk - converter in current-programmed continuous conduction mode.

(a) Buck converter with input filter
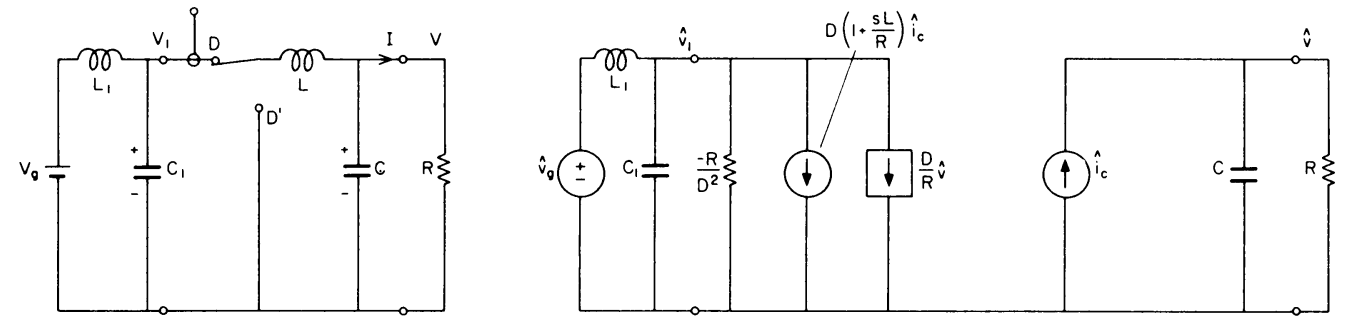

(b) Boost converter
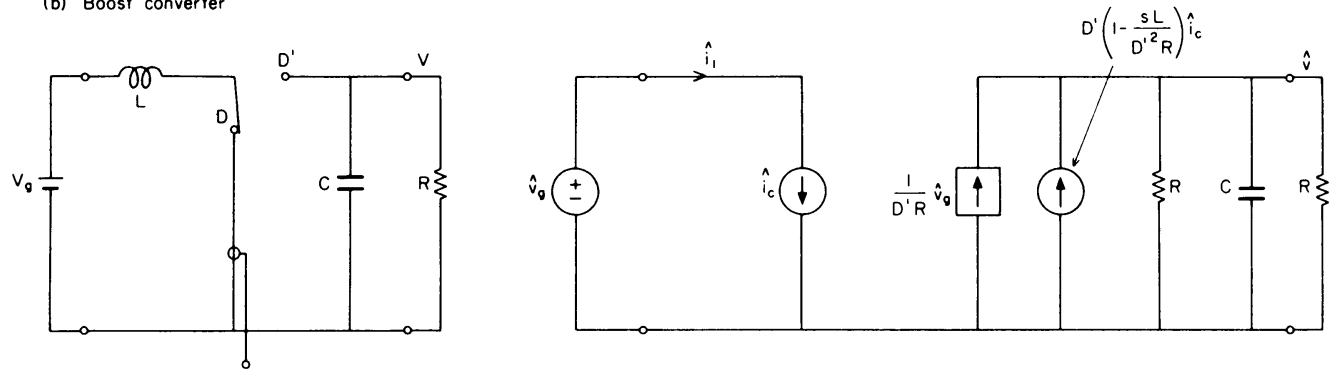

(c) Buck-boost converter with input filter
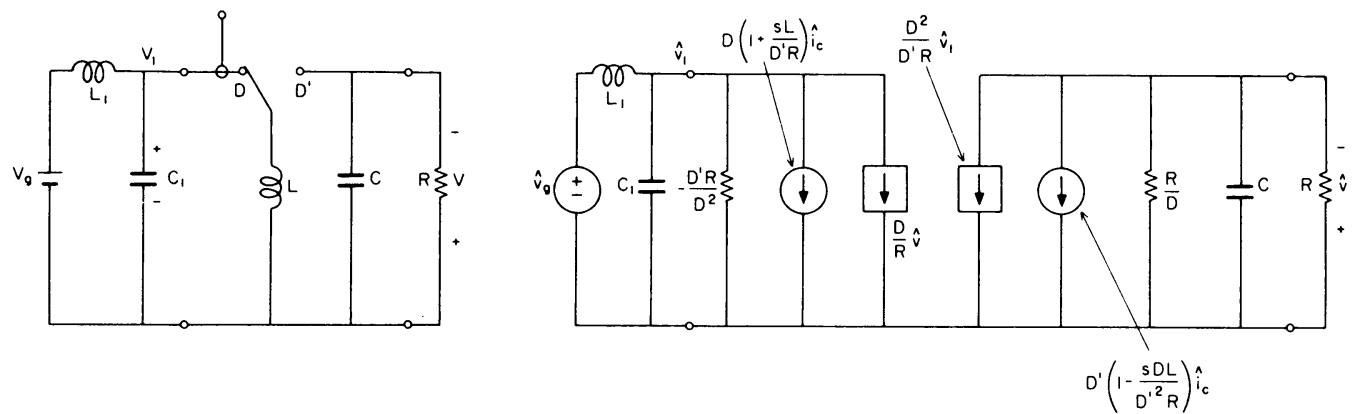

Fig. 14 Basic circuits and their "simple" small-signal equivalent circuit models for the buck, boost, and buck-boost converters in current-programmed continuous conduction mode. 
in a buck or buck-boost converter, the input properties of these converters cannot be carried through the analysis in the absence of an input filter. Therefore, input LC filters are added in these two cases so that the equivalent circuit models accurately represent the input properties.

\subsection{Comparison of Dynamics in Current-Programmed} and Duty-Ratio Programmed Modes

Equivalent circuit models for the buck, boost, buck-boost, and Cuk converters have been developed and extensively discussed for the duty-ratio programmed mode in both continuous inductor conduction $[1,5,6,7]$, and in discontinuous conduction [2, 8]. The salient feature of all these converters is that the resulting control-to-output transfer function basically has two poles in the continuous conduction mode, plus a right half-plane zero in the case of the boost and buck-boost converters, in contrast to the basically one-pole response in the discontinuous conduction mode. A combination of both these responses appears in the equivalent circuit models developed here for the currentprogrammed continuous conduction mode.

The one-pole response is seen most clearly from the model of the buck converter in currentprogrammed continuous conduction mode shown in Fig. 14(a). The control-to-output transfer functions is

$$
\hat{\mathrm{v}}_{\mathrm{i}}=\frac{R}{1+\mathrm{SCR}}
$$

From Fig. 14(b), it is seen that the boost converter also has a one-pole control-to-output response, with addition of the same right halfplane zero as in the duty-ratio programmed mode [1]. The same remarks apply to the buck-boost converter modelled in Fig. 14(c).

All three converters in current-programmed continuous conduction mode have the same general form of model as for the duty ratio programmed discontinuous conduction mode [2]. That of the buck-boost converter in Fig. 14(c) contains all the elements of the general model, whereas some of the elements are missing in the models of the buck and boost converters in Figs. 14(a) and $14(\mathrm{~b})$.

The one-pole control-to-output response of the buck, boost, and buck-boost converters is obvious because of the absence of the converter inductor from the models of Fig. 14. In the model of the Cuk converter in current-programmed continuous conduction mode in $\mathrm{Fig}$. 13, both the input and output inductors appear explicitly, and it is not so obvious that the control-to-output response is in fact also basically one-pole.

To see this result, first ignore the dependent current generator bridging $C_{1}$ in Fig. 13 . Then, below the resonant - frequency of $\mathrm{L}_{1} \mathrm{C}_{1}, \mathrm{C}_{1}$ is open and the generator $D^{\prime} \hat{i}_{C}$ feeds directly through $\mathrm{L}_{2}$ so that

$$
\frac{\hat{v}}{\hat{i}_{C}}=\frac{D^{\prime} R}{1+\mathrm{sC}_{2} \mathrm{R}^{-}}
$$

Thus, the value of $\mathrm{L}_{2}$ is immaterial since its current is fixed at $\mathrm{D} \cdot \hat{\mathrm{i}}$, and a single-pole response results. At $\mathrm{f}^{\prime}$ requencies above the $\mathrm{L}_{1} \mathrm{C}_{1}$ resonance, $C_{1}$ shorts and places the two generators $D \hat{i}$ and $D ' \hat{i}^{1}$ in parallel; then, the resulting total generător current $\hat{i}_{c}$ divides between $L_{1}$ and $\mathrm{L}_{2}$ so that approximately

$$
\hat{\mathrm{v}}_{\mathrm{i}_{c}}=\frac{\mathrm{L}_{1}}{\mathrm{~L}_{1}+\mathrm{L}_{2}} \frac{\mathrm{R}}{\mathrm{I}+\mathrm{sC}_{2} \mathrm{R}}
$$

Thus, essentially a one-pole response occurs, with a "glitch" in the neighborhood of the corner frequency of $\mathrm{L}_{1}$ and $\mathrm{C}_{1}$, the size of the glitch being greater the higher the Q-factor of the $\mathrm{L}_{1} \mathrm{C}$ resonance. This is quite similar to the gfitch effect observed in the duty-ratio programmed mode [6].

Relatively minor modifications occur in the above results when the dependent generator across $\mathrm{C}_{1}$ in Fig. 13 is accounted for. In fact, at high frequencies this generator has no effect at all, since it is shorted by $C_{1}$. At low frequencies, the node voltage $\hat{v}_{\text {a }}$ becomes much smaller than $\hat{v}_{b}$ so that the dependent generator effectively be- $b$ comes $\left(D^{\prime} / R_{N}\right) \hat{v}_{b}$ in parallel with the independent generator $D^{N} \hat{i}$ or, equivalently, a resistance $\mathrm{R}_{\mathrm{N}} / \mathrm{D}^{\prime} \operatorname{across}^{\mathrm{C}} \mathrm{D}^{\prime} \hat{\mathrm{i}}_{\mathrm{C}}$. By $(32), \mathrm{R}_{\mathrm{N}} / \mathrm{D}^{\prime}=\mathrm{R} / \mathrm{D}$, so this resistance introduces a second pole in the control-to-output transfer function at $\mathrm{R} / \mathrm{DL}_{2}$. Normally, the frequency of this pole is much higher than the corner frequency of $\mathrm{L}_{1}$ and $\mathrm{C}_{1}$, above which, as already seen, the dependent generator across $\mathrm{C}_{1}$ is effectively shorted; hence, the conclusion is that the dependent current generator has little effect upon the qualitative control-to-output transfer function, which is essentially a one-pole response plus a glitch at the $\mathrm{L}_{1} \mathrm{C}_{1}$ resonance.

In all four of the converters, the reduction of the control-to-output transfer function from a two-pole response in the duty ratio programmed continuous inductor current mode to a one-pole response in the current-programmed continuous conduction mode is a direct consequence of the programmed inductor current being constrained to be equal to the control signal and hence ceasing to be an independent state variable. This reduction of the order of the system greatly simplifies the design of a regulator loop. Thus, the same desirable one-pole loop response is obtained as in the duty ratio programmed discontinuous inductor current mode, but without the disadvantage of high ripple.

\section{IMPROVED ACCURACY MODELS}

The equivalent circuit models of Figs. 13 and 14 are satisfactory for most practical design purposes, as will be seen from the experimental data presented in Section 5. However, if the 
application does require more accuracy than can be achieved with the equivalent circuit models given thus far, more accurate models are available. The improvement is accomplished by altering the control constraint (15) so as to give a better description of the effect of the current loop; previously, it was assumed that variations in the programmed current followed variations in the control signal exactly. A more careful analysis is now undertaken.

Figure 15 shows the actual detailed relationship between the control signal and the programmed current. An artificial ramp of constant slope $\mathrm{m}$, added to the switch current, is also included.

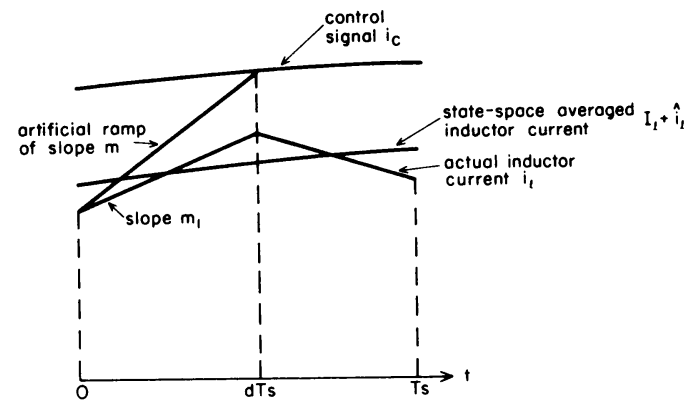

Fig. 15 More accurate relationship between programmed current $i_{l}$ and control signal $i_{c}$. See Fig. 9.

Since the state-space averaged current $\mathrm{I}_{f}+\hat{\mathrm{i}}_{\ell}$ passes through the midpoint of the actuaf current waveform, it is clear that

$$
\mathrm{I}_{\ell}+\hat{i}_{\ell}=\mathrm{i}_{\mathrm{c}}-\mathrm{m}_{1} \frac{\mathrm{dT} \mathrm{s}}{2}-\mathrm{mdT}_{\mathrm{s}}
$$

The first-order perturbation of this equation gives

$$
\hat{i}_{l}=\hat{i}_{c}-D T_{s} \frac{\hat{m}_{1}}{2}-\left(\frac{m_{1}}{2}+m\right) T_{s} \hat{d}
$$

The second and third terms on the right-hand side are the corrections to the simple control constraint (19). The analysis then proceeds as described in Section 3.3, with use of the duty ratio expression (16) to eliminate $\hat{d}$ from (39) and to arrive at an expression for $\hat{i}_{\ell}$ of the form of the auxiliary relation (18). "At this point, since the models previously found used the relation $\hat{i}_{\ell}=\hat{i}_{c}$, the $\hat{i}_{\text {generators of these }}$ models are simply replaced fy the expressions corresponding to (18) that were found above. The result is a model with the same basic topology as that of the equivalent circuits found in Section 3.4 .

In general, frequency dependent terms appear in the more accurate expression for $\hat{i}_{\ell}$. These dependencies indicate that the programmed current is not entirely eliminated as a state, but that its effects are only noticeable at frequencies approaching the switching frequency. Since system bandwidth is usually kept well below the switching frequency, these terms are safely neglected.

This more accurate version of the modelling technique has been applied to all four of the converters considered earlier. In each case, the slope of the artificial ramp was chosen to be equal to the falling slope of the programmed inductor current, as discussed in Section 2. Correction terms which would be effective only in the neighborhood of the switching frequency were neglected. The results are summarized in Fig. 16 for the Cuk converter and in Fig. 17 for the other three converters.

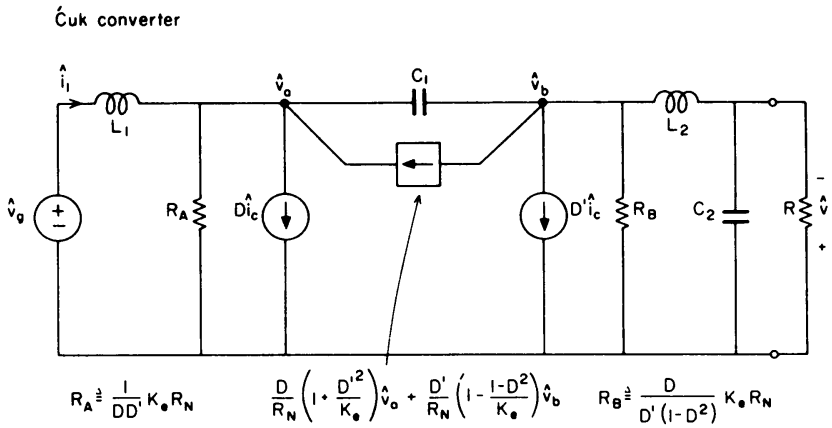

Parameters:

$R_{N}=\frac{\text { sum of } d c \text { input and output voltages }}{\text { sum of } d c \text { input and output currents }}$

$$
\triangleq \frac{V_{g}+V}{I_{l}+I}=\frac{D^{\prime}}{D} \frac{V}{I}=\frac{D^{\prime}}{D} R
$$

where

$$
\begin{aligned}
& R=\frac{d c \text { output voltage }}{d c \text { output current }} \triangleq \frac{V}{I} \\
& K_{e}=\text { inductor conduction parameter } \triangleq \frac{2\left(L_{1}|| L_{2}\right)}{R T_{S}} \\
& K_{\text {crit }}=D^{\prime 2}
\end{aligned}
$$

Fig. 16 "Extended" small-signal equivalent circuit model for the cuk converter in currentprogramed continuous conduction mode. Reduces to the "simple" model of Fig. 13 for $K_{e} \rightarrow \infty$ (deep into continuous conduction).

In the extended models for the buck, boost, and buck-boost converters in Fig. 17 the differences from the corresponding models of Fig. 14 are expressed in terms of a parameter $K$ defined as

$$
\mathrm{K} \triangleq \frac{2 \mathrm{~L}}{\mathrm{RT}_{\mathrm{S}}}=\frac{2 \mathrm{LI}}{\mathrm{VT}_{\mathrm{S}}}
$$

where $T$ is the switching period. For $\mathrm{K}$ sufficiently large, the models of Fig. 17 reduce to those of Fig. 14 . 
(a) Buck converter with input filter. $K_{c r i t}=D^{\prime}$

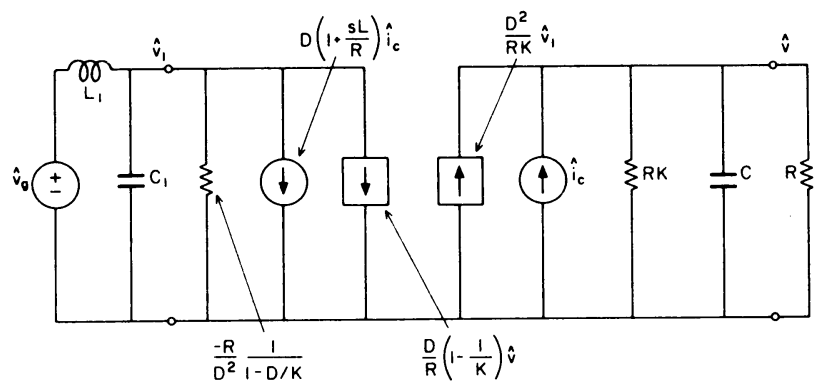

(b) Boost converter. $K_{c r i t}=D D^{\prime 2}$

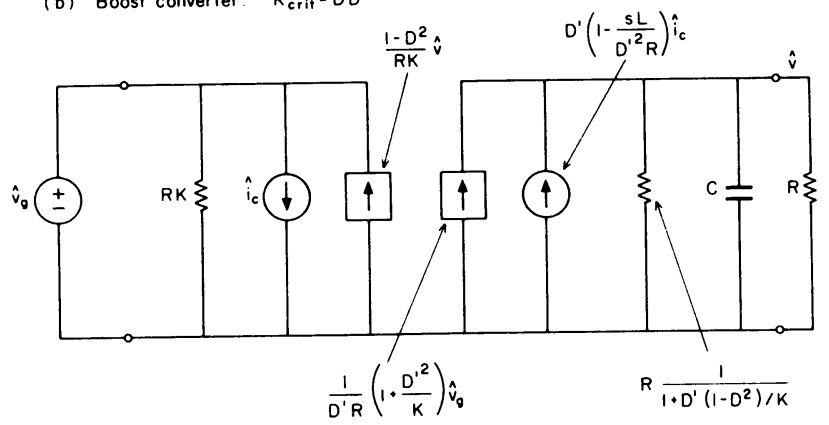

(c) Buck-boost converter with input filter. $K_{\text {crit }}=D^{\prime 2}$

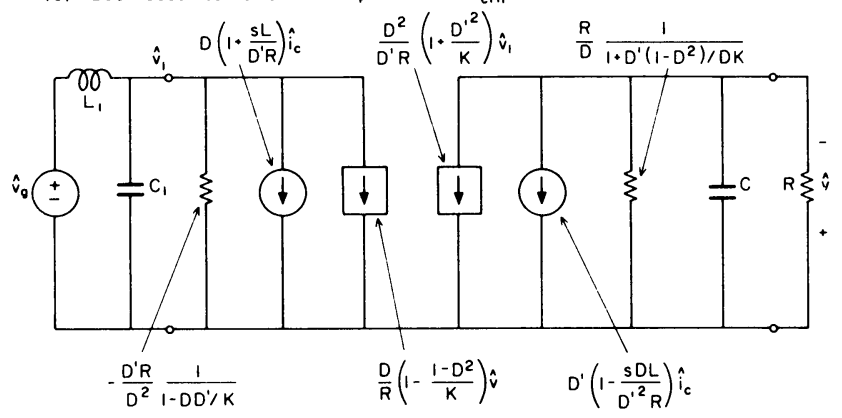

(d) Parameters for all three converters:

$$
\begin{aligned}
& \mathrm{R}=\frac{\mathrm{dc} \text { output voltage }}{\mathrm{dc} \text { output current }} \triangleq \frac{\mathrm{V}}{\mathrm{I}} \\
& \mathrm{K}=\text { inductor conduction parameter } \triangleq \frac{2 \mathrm{~L}}{\mathrm{RT}} \text { s }
\end{aligned}
$$

Fig. 17 "Extended" small-signal equivalent-circuit models for the buck, boost, and buck-boost converters in current-programed continuous conduction mode. Reduce to the "simple" models of Fig. 14 for $K \rightarrow \infty$ (deep into continuous conduction).

The differences between the models of Fig. 14 and 17 are of two kinds: a noninfinite $\mathrm{K}$ modifies the values of some existing elements, and also introduces some elements absent, in the simple mode1. It is seen that all three converters now require the "full" model previously needed only for the buck-boost converter in Fig. 14(c). For the boost converter, the simple model predicts infinite open-loop input impedance if the control signal is held constant, because the input current is the programmed inductor current and is thus constrained to the fixed control signal. However, as the input voltage varies, the slope of the inductor current also changes and, as a result, the average input current varies slightly with the input voltage. Hence the input impedance is actually finite, and the additional elements in the more accurate model of the boost converter account for this effect. Likewise, the simple model of the current-programmed buck converter predicts infinite line rejection but, for the same reasons that the boost converter input impedance is not infinite, a source disturbance in a currentprogrammed buck converter results in a small change in the output voltage. The additional generator in the output port of the buck converter more accurate model takes this phenomenon into account.

The significance of the parameter $K$ is that it is a measure of the ratio of the inductor dc' current, proportional to I, to its switchingfrequency ac ripple current, which is proportional to $(\mathrm{V} / \mathrm{L}) \mathrm{T}_{\mathrm{s}}$. Thus, $\mathrm{K}$ is large when the inductor dc current is large compared to its ripple current. As the dc load resistance $R=V / I$ becomes larger, the converter approaches the discontinuous inductor current mode as $\mathrm{K}$ becomes smaller. It is no coincidence that $K$ is precisely the "inductor conduction parameter" defined in [2], whose value determines whether the converter operates in the continuous or in the discontinuous conduction mode. As shown in [2], $\mathrm{K}>\mathrm{K}$ for the converter to operate in the continuous conduction mode. The values of $\mathrm{K}$ for the three converters are also indicated in Fig. 17 .

In the extended model for the Ćuk converter in Fig. 16 the differences from the simple model of Fig. 13 are also expressed in terms of the corresponding "inductor conduction parameter" defined in [8] as

$$
\mathrm{K}_{\mathrm{e}} \triangleq \frac{2\left(\mathrm{~L}_{1}|| \mathrm{L}_{2}\right)}{\mathrm{RT}_{\mathrm{s}}}=\frac{2\left(\mathrm{~L}_{1}|| \mathrm{L}_{2}\right) \mathrm{I}}{\mathrm{VT}_{\mathrm{s}}}
$$

Again, a noninfinite $\mathrm{K}$ leads to a modified value of one element, the dependent current generator across $C_{1}$, and to new elements $R_{A}$ and $R_{B}$. Nevertheless, these corrections do not alter the nature of the previous qualitative discussion concerning the one-pole form of the control-to-output transfer function.

It is seen that the dynamic properties of all four converters in the current-programmed continuous inductor current mode are very similar to those in the duty ratio programmed discontinuous current mode. However, it is interesting to note that the dynamic properties in the duty ratio programmed continuous conduction mode are independent of the inductor conduction parameter (that is, of dc load resistance), whereas the dynamic properties in the current-programmed continuous conduction mode become progressively more affected as discontinuous conduction is approached. That is, the elements involving $\mathrm{K}_{\mathrm{e}}$ or $\mathrm{K}$ in the models of Figs. 16 and 17 become progressively more dependent on $\mathrm{K}$ or $\mathrm{K}$ as this parameter decreases towards its critical value. 


\section{EXPERIMENTAL VERIFICATION}

A Ćuk converter operated in current-programmed mode was built to test the accuracy of the equivalent circuit model. The circuit diagram is shown in Fig. 18. Also constructed was a boost converter, with similar control circuitry. Since the purpose was to compare measured transfer functions with theoretical predictions, output voltage feedback was not applied. In the following, "open 1oop" refers to this absence of voltage regulator feedback.

The implementation of the current loop was patterned after that of [4]. The switch current is sensed by a current transformer, wound $\mathrm{N}_{2}: \mathrm{N}_{1}=100: 1$ on a Ferroxcube $768 \mathrm{~T} 188-3 \mathrm{E} 2 \mathrm{~A}$ ferrite toroid. The transformer secondary is fed into the emitter-base terminals of a high gain PNP transistor (2N2907A) resulting in unity current gain at the collector. This arrangement fixes the voltage across the transformer secondary to a single diode drop. An artificial ramp with slope adjusted according to the results of Section 2 is added to the switch current replica, the summing occurring at a 150-ohm resistor $R_{c}$. The resulting voltage is compared with the control signal by an LM 311 comparator. A D-flip-flop is clocked to close the power switch when the current ramp reaches the level of the control signal.

The Cuk converter was operated at a switching frequency of $70 \mathrm{kHz}$, with a nominal duty ratio of 0.6 . Open loop input admittance $\hat{i}_{1} / \hat{v}_{\text {g }}$, line-tooutput transfer function $\hat{v} / \hat{v}$, and cohtro1-tooutput transfer function $\hat{v} / \hat{i}_{c}{ }_{c}$ ' were measured with an HP 3040A Network Analyzer, using standard techniques for the measurement of such quantities in the presence of switching noise $[9,10]$. For convenience, the control signal is taken as the voltage $\hat{v}_{\text {into }}$ the comparator, and the controlto-output ${ }^{c}$ transfer function is actually measured as $\hat{v} / \hat{v}$. From Fig. 18, the relation between the

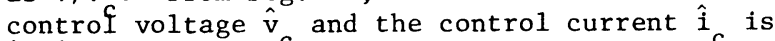
$\hat{\mathrm{i}}_{\mathrm{c}} / \hat{\mathrm{v}}_{\mathrm{c}}=\mathrm{N}_{2} / \mathrm{N}_{1} \mathrm{R}={ }^{c} 100 / 150=1 / 1.5 \Omega$. The experimentå 1 data arê presented in Fig. 19, along with theoretical predictions produced by the SPICE2 circuit analysis program, based in the simple model of Fig. 13. The value of $R_{N}$ from (32) is $\mathrm{R}_{\mathrm{N}}=(1-0.6) 19 / 0.6=13 \Omega$.

While all the zeros of these three transfer functions remain in the same places as their counterparts in the conventional duty ratio programmed mode, one pole is removed in all cases owing to the current-programming effect. The winding resistances of the input and output inductors, $0.10-\mathrm{ohm}$ and $0.12-\mathrm{ohm}$ respectively, were included in the models as resistors in series with the inductors. Although these resistances provide a small degree of damping, the glitch in the control-to-output transfer function at the corner frequency of $L_{1}$ and $C_{1}$, at $1 / 2 \pi \sqrt{220 \mu \mathrm{H} \times 110 \mu \mathrm{F}}$ $=1.0 \mathrm{kHz}$, is substantial. $\mathrm{tt}$ is seen that the simple model of Fig. 13 provides satisfactory predictions except for the open-loop input admittance.

In Fig. 20 the same experimental data are shown together with the computer-predicted curves from the extended model of Fig. 16. From (41), the inductor conduction parameter is

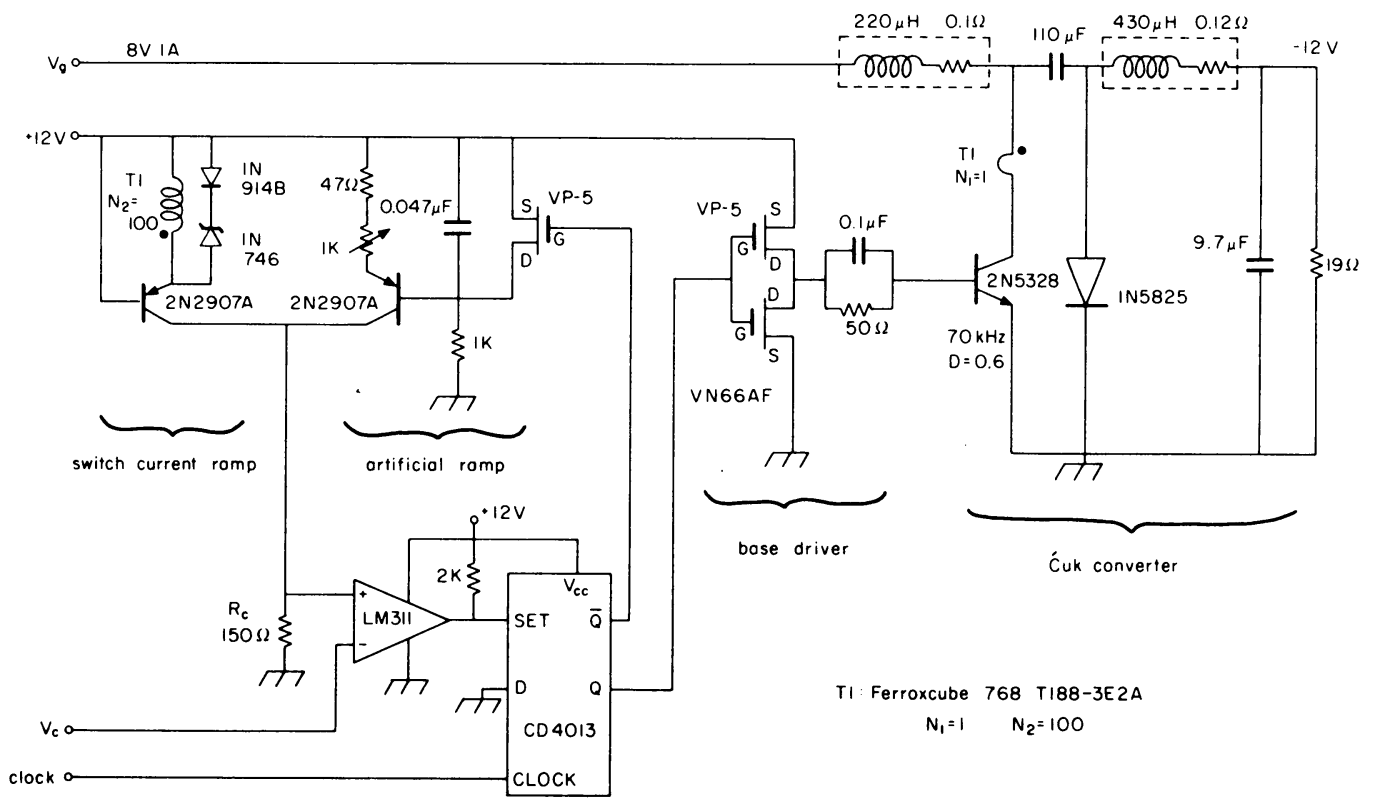

Fig. 18 Schematic of test circuit of an open-loop current-programmed cuk converter in continuous conduction mode. 

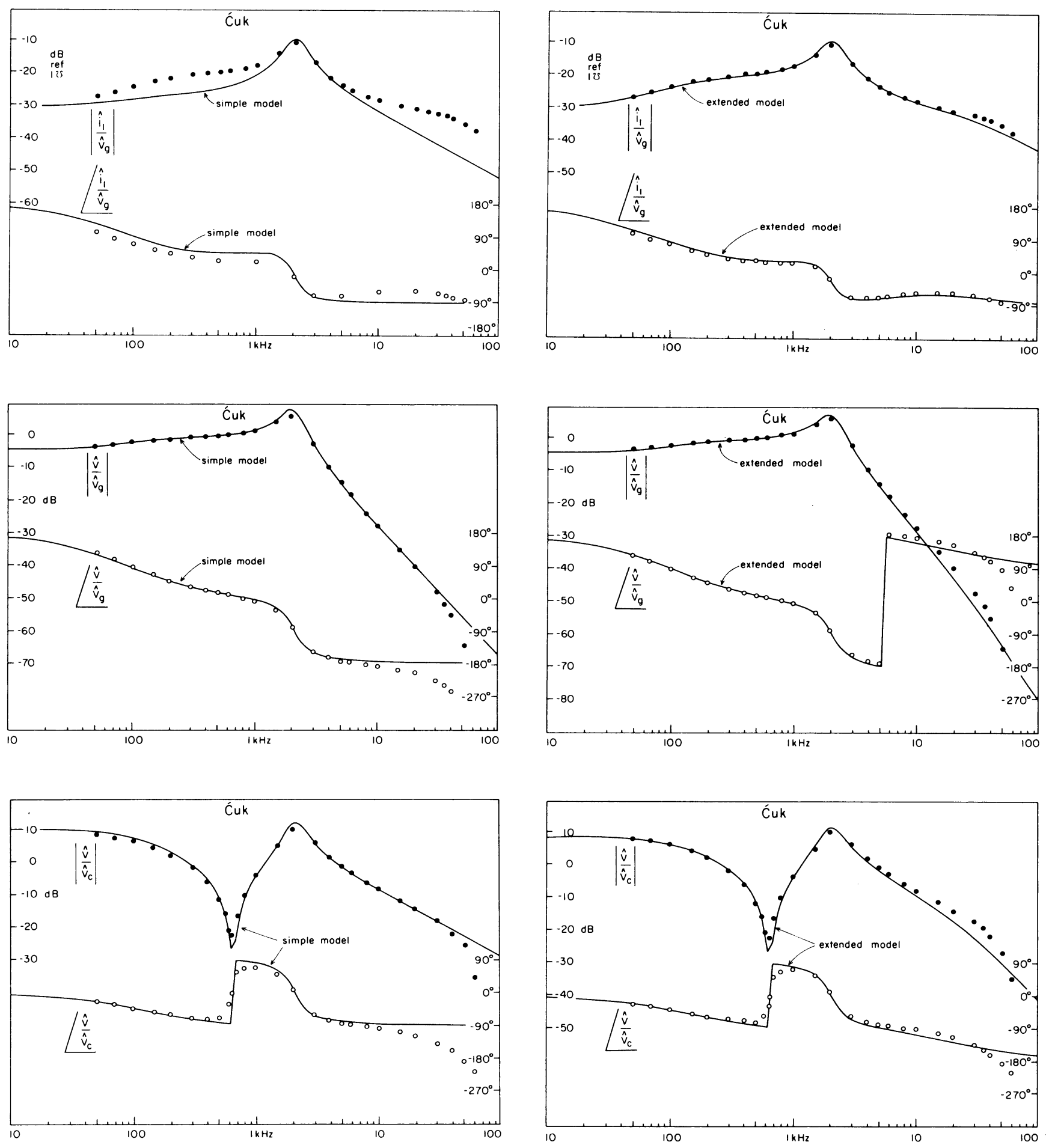

Fig. 19 Experimental data and computer predictions

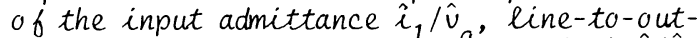
put transfer function (line rejection) $\hat{v} / \hat{v}_{g}$, and control-to-output transfer function $\hat{v} / \hat{v}$, for the Cuk converter of Fig. 18. The computer predictions are based on the "simple" model of Fig. 13.

Fig. 20 The same experimental data of Fig. 19 compared with the computer predictions based on the "extended" model of Fig. 16. 


$$
\mathrm{K}_{\mathrm{e}}=\frac{2(220 \mu \mathrm{H}|| 430 \mu \mathrm{H})}{19 \Omega(1 / 70 \mathrm{kHz})}=1.1
$$

For the operating point $\mathrm{D}=0.6$,

$$
\mathrm{K}_{\text {ecrit }}=\mathrm{D}^{\prime 2}=0.16
$$

so $\mathrm{K}_{\mathrm{f}}$ is not very large compared to $\mathrm{K}_{\text {ecrit }}$, and the resulting correction factors in the dependent current generator across $C_{1}$ are significant. The additional resistances in the model are

$$
\begin{aligned}
& \mathrm{R}_{\mathrm{A}}=\frac{1.1 \times 13}{0.6 \times 0.4}=60 \Omega \\
& \mathrm{R}_{\mathrm{B}}=\frac{0.6 \times 1.1 \times 13}{0.4(1-0.36)}=34 \Omega
\end{aligned}
$$

It is seen from Fig. 20 that the accuracy of the predicted input admittance results from the extended model is much improved. An extra pole at high frequency is produced in the more accurate model, but this effect cannot be given much importance, since other high frequency terms have previously been neglected in the process described in Section 4. Note that the apparent phase discontinuity in Fig. 20(b) is due to a limitation of the circuit analysis program, and does not represent an actual feature of the transfer function. In plotting the experimental data, a 360-degree phase shift has been added in order to follow this artificial discontinuity.

Although both the model of Fig. 13 and the extended model of Fig. 16 quite accurately predict the properties of the Cuk converter in current-programmed continuous inductor current mode, it is seen from the results of Figs. 19(c) and 20 (c) that the glitch in the control-tooutput transfer function is undeniably large. As mentioned, the size of the glitch can be reduced by addition of suitable damping of the LC resonances. This design objective has already been developed with respect to the similar problem that arises in the duty ratio programmed mode [6], in which suitable damping can be achieved by placing a resistance across one or both capacitances.

A similar damping means can be used for the current-programmed mode, and also leads to a simplification in the model. If a damping resistance $R_{1}$ is placed across the energy transfer capacitance $C_{1}$, as shown in the partial extended model of Fig. ${ }^{2} 1$, the resistance can be replaced by an equivalent current generator which can in turn be absorbed into the parallel dependent current generator, as also shown in Fig. 21. Then, if $R_{1}$ is small enough, the resulting single dependent current generator value is dominated by the $R_{1}$ contributions, and hence $R_{1}$ can be returned to its original explicit position across $C_{1}$, and the original dependent current generator can be omitted as having a negligible effect.

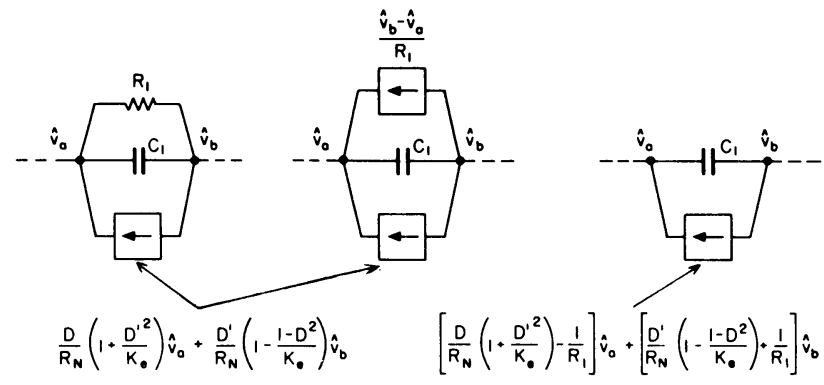

(o)

(b)

(c)

Fig. 21 The damping resistor $R$ of a 'Cuk converter can be absorbed into the current source across the energy transfer capacitor $C_{1}$.

The resulting simplified model is shown in Fig. 22. Omission of the dependent current generator is a considerable advantage, since it was the only element in the model whose effect upon the properties is not easily interpreted. The approximation is likely to be good in all cases where the damping resistance $R_{1}$ is small enough to reduce to invisibility the glitch in the control-to-output transfer function, as can be seen by consideration of the numerical values in the experimental circuit of Fig. 18. As previously determined, $R_{N}=13 \Omega$ and $\mathrm{K}=1.1$, so that with $\mathrm{D}=0.6$ the original dependent current generator in Fig. 15 is given by

$$
\begin{gathered}
\frac{0.6}{13}\left(1+\frac{0.16}{1.1}\right) \hat{\mathrm{v}}_{\mathrm{a}}+\frac{0.4}{13}\left(1-\frac{0.64}{1.1}\right) \hat{\mathrm{v}}_{\mathrm{b}} \\
=\frac{1}{19 \Omega} \hat{\mathrm{v}}_{\mathrm{a}}+\frac{1}{78 \Omega} \hat{\mathrm{v}}_{\mathrm{b}}
\end{gathered}
$$

To remove the undesirable glitch, $R_{1}$ must be sufficiently small to damp the $\mathrm{L}_{1} \mathrm{C}_{1}$ resonance to an effective $Q$ of order unity. The characteristic resistance of the $\mathrm{L}_{1} \mathrm{C}_{1}$ combination is $\sqrt{\mathrm{L}_{1} / \mathrm{C}_{1}}=$ $\sqrt{220 \mu \mathrm{H} / 110 \mu \mathrm{F}}=1.4 \Omega$, and so a value for $\mathrm{R}_{1}$ of this order of magnitude would clearly dominate the $19 \Omega$ and $78 \Omega$ contributions to the dependent current generator.

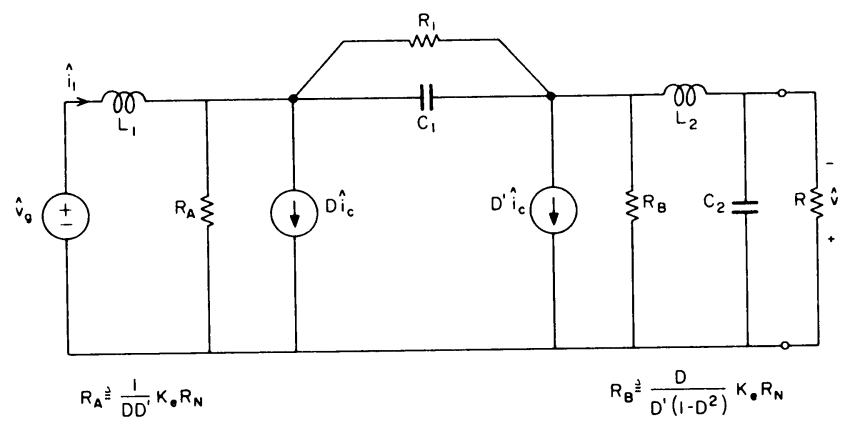

Fig. 22 More easily interpreted "extended" Cuk converter model of Fig. 16 in which a sufficiently small damping resistance $R_{1}$ added across $C_{1}$ permits the parallel current generator to be omitted. 
Another way of looking at the above result follows from recognition that the original dependent current generator across $C_{1}$ in the model acts similarly to a parallel damping resistance whose value is of the order of $R_{N}$; since $R_{N}$ is of order $R$, and since $R$ is usually large enough to correspond to only light damping, it follows that addition of explicit damping resistance $R_{1}$ will usually justify omission of the original dependent current generator from the model, as shown in Fig. 22 .

To illustrate how such damping can eliminate the glitch in the control-to-output transfer function, a resistor of $2.1 \Omega \mathrm{dc}$ blocked by a $900 \mu \mathrm{F}$ capacitor was placed across $C_{1}$ in the experimental circuit of Fig. 18, and a $10 \Omega$ resistor dc blocked by a $110 \mu \mathrm{F}$ capacitor was placed across $\mathrm{C}_{2}$. The resulting control-to-output transfer function data points are shown in Fig. 23, together with the computer predicted curves given by the model of Fig. 22 with omission not only of the dependent current generator, but also of the resistances $R_{A}=60 \Omega$ and $R_{B}=34 \Omega$. Since these resistances, as far as the control-to-output transfer function is concerned, merely produce a damping effect which, because of their large values, is small compared with that of $R_{1}=2.1 \Omega$, it is clear that the resistances $R_{A}$ and $R_{B}$ can also be neglected. This conclusion is verified by the good agreement between the experimental data points and the computer prediction in Fig. 23.

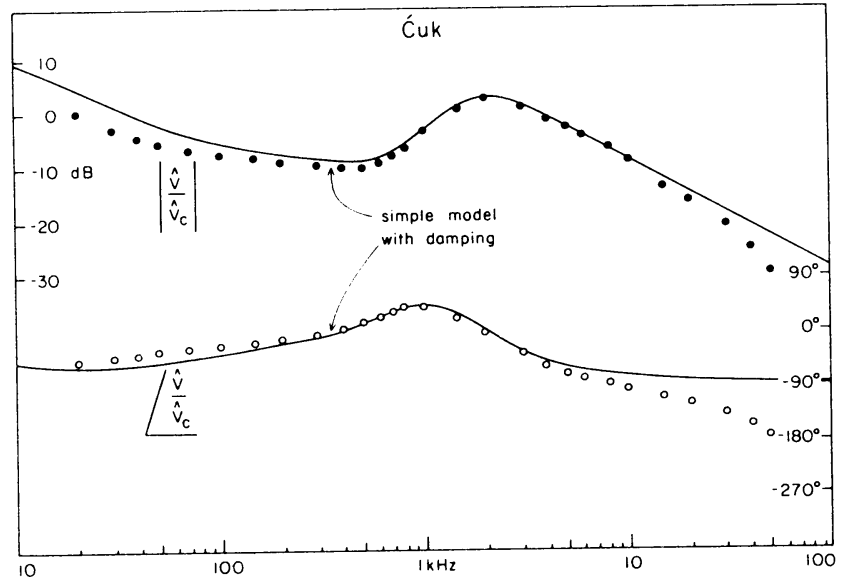

ig. 23 The glitch in the cuk converter controlto-output trans fer function of Fig. $19(\mathrm{c})$ is substantially reduced by addition of $d c$-blocked damping resistors across $C_{1}$ and $C_{2}$ respectively. Computer predicted values are from the model of Fig. 22 with $R_{1}=2.1 \Omega, R_{2}=10 \Omega$ across $C_{2}$, and with $R_{A}$ and $R_{B}$ ometted.

Experimental data for a current-programmed boost converter, as shown in Fig. 14(b), with $\mathrm{L}=390 \mu \mathrm{H}, \mathrm{C}=24 \mu \mathrm{F}, \mathrm{R}=75 \Omega$, and $\mathrm{V}=25 \mathrm{~V}$, operated at $70 \mathrm{kHz}$ with duty ratio of 0.55 are given in Fig.

24. The inductor conduction parameter $\mathrm{K}=2 \mathrm{~L} / \mathrm{RT}_{\mathrm{S}}=$ 0.72 again is not very large compared to $\mathrm{K}_{\mathrm{crit}}=$ 0.11 , so the extended model of Fig. 17(b) is necessary for accurate prediction. The theoretical
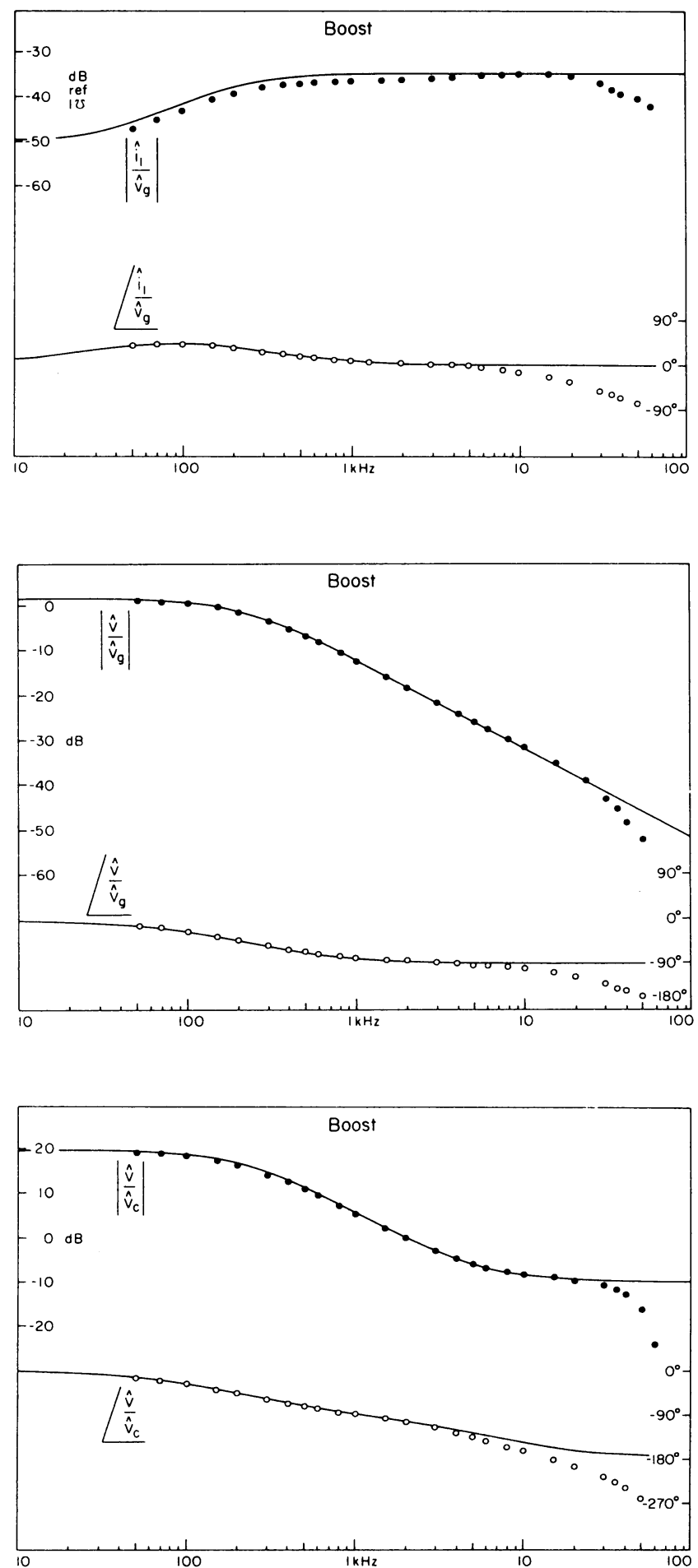

Fig. 24 Experimental data and computer predictions of $\hat{i}_{1} / \hat{v}, \hat{v} / \hat{v}$, and $\hat{v} / \hat{v}$ for a boost converter in eurrent-programed continuous conduction mode. The computer predictions are based on the model of Fig. 25. 
values in Fig. 24 are calculated using the model in Fig. 25. This model is equivalent to the model developed in Section 4 and presented in Fig. 17(b), but has been manipulated slightly to eliminate the frequency dependent generator, for the convenience of the SPICE2 program. Again, the zeros remain in the same places and the number of poles is reduced by one, compared with the corresponding transfer functions in the duty-ratio programmed mode. Satisfactory predictions are obtained up to about half the switching frequency.

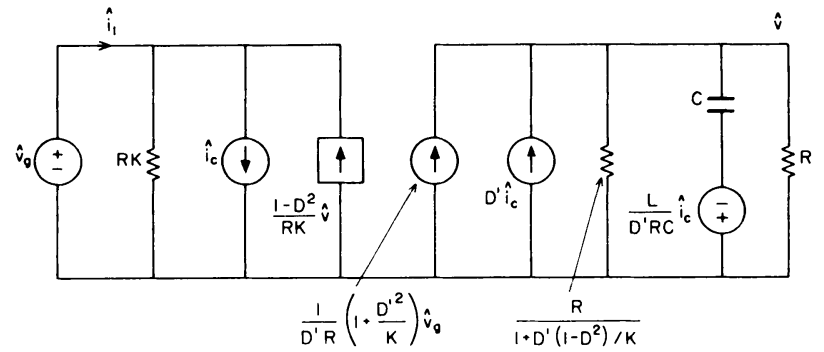

Fig. 25 Boost converter small-signal equivalentcircuit of Fig. 17(b), slightly manipulated for convenience of computer calculations.

\section{CONCLUSIONS}

A converter operated in the current-programmed mode has the properties of continuous switch protection, overload protection, equal load sharing in parallel operation, and simpler control dynamics than in the conventional duty-ratio programmed mode. However, in the course of development of a good design technique, two difficulties must be overcome: (1) the potential instability of the current loop when the duty ratio is greater than 0.5 , and (2) the lack of a complete equivalent circuit model which can guide the designs of a regulator feedback loop and an input filter.

Solutions to both problems have been presented in this paper, for any converter operated in constant-frequency, current-programmed continuous inductor current mode. In Section 2, a particular value of the artificial ramp slope is proposed, which guarantees not only stability, but also the fastest possible transient response of the programmed current. In Sections 3 and 4, a method is introduced which leads to a small-signal linear equivalent circuit model which represents both the input and the output properties of a converter operated in current-programmed continuous conduction mode. The method is an application of the state-space averaging technique, which describes the relationships between the variations of state variables, input voltage, and duty ratio around the operating point in a simple and elegant manner. An extra constraint on the inductor current is then imposed to reflect the nature of the current-programmed mode.
The model is developed in detail for the Cuk converter, and the results are also presented for the conventional buck, boost, and buck-boost converters. In all cases, the salient feature of the model for the current-programmed continuous conduction mode is that it predicts a basically one-pole response for the control-to-output transfer function. This is to be expected since, qualitatively, the programmed current feeds directly into the output capacitor producing the single pole, and the inductor current essentially ceases to be an independent state.

The model for current-programmed continuous conduction mode has the same one-pole control-tooutput response as does that for the duty ratio programmed discontinuous conduction mode, but it also contains the same right half-plane zeros as does the model for the conventional duty ratio programmed continuous conduction mode. In both modes, these (single) right half-plane zeros occur for the boost and buck-boost converters, but not for the buck.

In the Cuk converter, which contains an "inherent" input filter in addition to the "output" filter, there is a possibility of a pair of right half-plane zeros in the model for both the currentprogrammed and the duty ratio programmed continuous conduction modes. In both cases, this can arise because of an interaction between the input and output filters, and the pair of zeros can be moved to the left half-plane by suitable damping of one or both filters.

From another point of view, such damping essentially prevents the input filter from having any significant effect upon the control-to-output transfer characteristic, which consequently retains the essentially one-pole response.

Two forms of model for current-programmed continuous conduction mode are derived, a "simple" model and an "extended" model in which account is taken of the fact that the inductor current is not entirely removed as a state variable. The extended model reduces to the simple model when the inductor ripple current is vanishingly small compared to its dc component, that is, when the converter operates deep in the continuous conduction mode. The discrepancies between the extended and the simple models become progressively more severe as discontinuous conduction is approached, and in fact the discrepancies are quantitatively expressed in terms of the parameter $\mathrm{K}$ previously introduced as an "inductor conduction parameter" in models of converters operated in duty ratio programmed discontinuous conduction mode.

Experimental measurements of converter input admittance, line rejection, and control-to-output transfer function agree well with computer predictions from both the simple and extended models for the Cuk converter in current-programmed continuous conduction mode, and also for the boost converter. It is also shown that a particularly simple form of the model for the Cuk converter 
results when sufficient damping of the input filter is incorporated, as is normally required for acceptable performance.

The models developed for converters in currentprogrammed continuous conduction permit informed design of loop gain, input and output impedances, line rejection, and other performance properties to be undertaken for regulators containing converters operated in this mode.

\section{REFERENCES}

[1] R. D. Middlebrook and Slobodan Cuk, "A General Unified Approach to Modelling Switching-Converter Power Stages," IEEE Power Electronics Specialists Conference, 1976 Record, pp. 18-34, (IEEE Publication 76CH1084-3 AES); also International J. of Electronics, vol. 42, no. 6, pp. 521-550, June 1977.

[2] Sloblodan Ćuk and R. D. Middlebrook, "A General Unified Approach to Modelling Switching Dc-to-Dc Converters in Discontinuous Conduction Mode," IEEE Power Electronics Specialists Conference, 1977 Record, pp. 36-57, (IEEE Pub1ication 77CH 1213-8 AES).

[3] A. Capel, G. Ferrante, D. O'Sullivan, and A. Weinberg, "Application of the Injected Current Model for the Dynamic Analysis of Switching Regulators with the New Concept of LC $^{3}$ Modulator," IEEE Power Electronics Specialists Conference, 1978 Record, pp. 135147, (IEEE Publication 78CH1337-5 AES).

[4] Cecil W. Deisch, "Simple Switching Control Method Changes Power Converter into à Current Source," IEEE Power Electronics Specialists Conference, 1978 Record, pp. 300-306, (IEEE Publication 78CH1337-5 AES).

[5] Slobodan Ćuk and R. D. Middlebrook, "A New Optimum Topology Switching Dc-to-Dc Converter," IEEE Power Electronics Specialists Conference, 1977 Record, pp. 160-179 (IEEE Publication 77CH1213-8 AES).

[6] R. D, Middlebrook, "Modelling and Design of the Cuk Converter," Proc. Sixth National Solid-State Power Conversion Conference (Powercon 6), pp. G3.1-G3.14, May 1979.

[7] R. D. Middlebrook, "Design Techniques for Preventing Input-Filter Oscillations in Switched-Mode Regulators," Proc. Fifth National Solid-State Power Conversion Conference (Powercon 5), pp. A3.1-A3.16, May 1978.
[8] Slobodan Ćuk, "Discontinuous Inductor Current Mode in the Optimum Topology Switching Converter," IEEE Power Electronics Specialists Conference, 1978 Record, pp. 105-123, (IEEE Publication 78CH1337-5 AES).

[9] R. D. Middlebrook, "Measurement of Loop Gain in Feedback Systems," International J. of Electronics, vol. 38, no. 4, pp. 485-512, April 1975.

[10] R. D. Middlebrook, "Improved-Accuracy Phase Angle Measurement," International J. of Electronics, vol. 40 , no. 1, pp. 1-4, Jan. 1976. 